\title{
Taxonomia do gênero Euploca Nutt. (Heliotropiaceae) no Brasil ${ }^{1}$
}

\author{
José Iranildo Miranda de Melo ${ }^{2,4}$ e João Semir ${ }^{3}$
}

Aceito em 6/05/2008. Aceito em 1/06/2009

RESUMO - (Taxonomia do gênero Euploca Nutt. [Heliotropiaceae] no Brasil). O presente trabalho trata do estudo taxonômico do gênero Euploca (Heliotropiaceae) no Brasil, sendo registradas 17 espécies. É apresentada chave para o reconhecimento, descrições, ilustrações e comentários, além de dados de distribuição, habitat, floração e frutificação para as espécies.

Palavras-chave: Heliotropiaceae, Euploca, morfologia, taxonomia, Brasil

ABSTRACT - (Taxonomy of the genus Euploca Nutt. [Heliotropiaceae] in Brazil). This work deals with a taxonomic study of the genus Euploca (Heliotropiaceae) in Brazil; seventeen species are recorded. A keyfor identification, descriptions, illustrations and comments, besides distribution, habitat, flowering and fruiting data for the species are presented.

Key words: Heliotropiaceae, Euploca, morphology, taxonomy, Brazil

\section{Introdução}

O gênero Euploca foi estabelecido por Nuttall (1837), com base em Euploca convolvulacea Nutt. Posteriormente, Euploca foi colocado sob Heliotropium (Gray 1874) e, os tratamentos subseqüentes consideraram-no neste gênero. Recentemente, Hilger \& Diane (2003) baseando-se em caracteres moleculares, morfológicos e anatômicos revalidaram Euploca, considerando-o na família Heliotropiaceae (Böhle \& Hilger 1997; Gottschling et al. 2001).

Reúne aproximadamente 100 espécies, dispersas nas regiões tropicais, subtropicais e temperadas, com centros de diversidade na África, Austrália e América Tropical (Diane et al. com. pess.), especialmente na América do Sul e no México. Seus representantes são predominantemente herbáceos, subarbustivos ou raramente arbustivos; inflorescências levemente ou fortemente escorpióides, com ou sem brácteas, e menos freqüentemente com flores axilares ou supra-axilares, brancas, com fauce amarela ou púrpura, ou mais raramente inteiramente amarelas; estames sésseis ou subsésseis, com anteras conatas apresentando tricomas e/ou glândulas no ápice; estigma com a porção não receptiva aneliforme, basal e a região receptiva do pólen geralmente cônica, levemente bífida ou até tetráfida no ápice; fruto esquizocárpico, com quatro núculas, sendo os caracteres carpológicos de grande importância para a delimitação das suas espécies.

Os trabalhos clássicos que enfocam Euploca (como sinônimo de Heliotropium) foram elaborados por De Candolle (1845), Fresenius (1857), Bentham \& Höoker (1873), Gürke (1893), Dalla Torre \& Harms (1900) e Johnston (1928). Outras importantes contribuições sobre a taxonomia deste gênero foram produzidas por: Johnston (1935; 1949; 1951), Gangui (1955), Riedl (1966), Fröhlich (1978), Craven (1996), Akhani \& Förther (1994) e Förther (1998).

$\mathrm{Na}$ América do Sul, os tratamentos que incluem Euploca (como sinônimo de Heliotropium) foram elaborados por
Johnston (1928), Gangui (1955), Macbride (1960) e Rodríguez (1993). No Brasil, são mencionadas principalmente em floras locais, flórulas e "checklists" que englobam, sobremaneira, as regiões Nordeste, Centro-Oeste, Sudeste e Sul: Smith (1970), Guimarães et al. (1971), Harvey (1995), Dubs (1998), Sano \& Almeida (1998), Munhoz \& Proença (1998), Mendonça et al. (2000), Nagatani \& Rossi (2000), Melo \& França (2003), Zappi et al. (2003), Melo $\&$ Sales (2004; 2005), Melo (2006), Melo (no prelo, com pess.), Melo \& Andrade (2007) e Melo \& Lyra-Lemos (no prelo, com pess.). No entanto, o tratamento mais abrangente sobre as Euploca no Brasil, ainda é o elaborado por Fresenius (1857) na Flora Brasiliensis, considerando-as sob Schleidenia.

Estudos filogenéticos recentes (Diane et al. 2002; Hilger \& Diane 2003) utilizando o espaçador gênico ITS1 (Internal Transcribed Spacer), verificaram que Heliotropium é parafilético e Euploca constitui um clado monofilético, incluindo as espécies de Heliotropium sect. Orthostachys R. Br., Hilgeria Förther e Schleidenia Endl. Por esta razão, Hilger \& Diane (2003) restabeleceram o gênero Euploca e propuseram novas combinações em espécies desse gênero.

O trabalho apresenta o estudo taxonômico do gênero Euploca no Brasil com base em caracteres morfológicos, com o objetivo de reconhecer, fornecer descrições, ilustrações e comentários para as espécies do gênero, estabelecer novas combinações e espécies, além de atualizar a sua distribuição geográfica.

\section{Material e métodos}

Estudos de campo - foram realizados nos estados da BA, CE, PB, PE e $\mathrm{RN}$, na região Nordeste. Esta etapa teve como finalidade a observação das populações 'in loco' e obtenção de espécimes para realização de estudos morfológicos, sendo observados, principalmente, os habitats preferenciais das espécies de Euploca. Os espécimes coletados foram processados segundo os métodos usuais em taxonomia vegetal (Bridson \& Forman 1998). As coleções foram incorporadas ao acervo do Herbário Professor

\footnotetext{
1 Parte da Tese de Doutorado do primeiro Autor

2 Universidade Estadual da Paraíba, Centro de Ciências Biológicas e da Saúde, Departamento de Biologia, Campina Grande, PB, Brasil.

3 Universidade Estadual de Campinas, Instituto de Biologia, Departamento de Botânica, Campinas, SP, Brasil.

4 Autor para correspondência: iranildo_melo@hotmail.com
} 
Vasconcelos-Sobrinho (PEUFR) da Universidade Federal Rural de Pernambuco (UFRPE), Recife, PE.

Tratamento taxonômico - baseou-se nos trabalhos de Johnston (1928), Frohlich (1978), Förther (1998) e, especialmente, Hilger \& Diane (2003). A análise morfológica comparativa foi realizada no Laboratório de Taxonomia Vegetal (LATAV) e no Herbário PEUFR, Departamento de Biologia, e no Herbário Sérgio Tavares (HST), Departamento de Engenharia Florestal, pertencentes à UFRPE.

Foram examinados aproximadamente 1500 espécimes obtidos por empréstimos e/ou doações de herbários nacionais e internacionais ou através de visitas a herbários nacionais, listados a seguir: ALCB, BAB, BHCB, CEN, CEPEC, CESJ, CH*, COR, CPAP, CTES, EAC, ESA, GH, GUA, HAS, HBH*, HBR, HRB, HRCB, HST*, HTINS*, HUEFS, HUFU, IAC, IAN, IBGE, ICN, INPA, IPA, JPB, K, MAC, MBM, MBML, MG, MHN*, MO, MOSS*, MUFAL*, MY, NY, PACA, PEL, PEUFR, R, RB, RFA, PORT, SJRP, SP, SPF, SPSF, TEPB, UB, UCS, UEC, UFMS*, UFP, UFRN, US, VEN, VIC e VIES*. Os acrônimos foram mencionados segundo Holmgren et al. (2006), exceto os marcados com asterisco. Foram consultados ainda espécimes digitalizados, especialmente typus, provenientes do Royal Botanic Gardens, Kew (K) e, também, da Universidade de Harvard (GH) [http: //www.huh.harvard.edu/databases/specimen_index.html].

A grafia dos nomes dos autores foi citada segundo Brumitt \& Powell (1992). Para a elaboração das descrições e ilustrações foram utilizados espécimes obtidos em campo, herborizados e/ou acondicionados em meio líquido. As estruturas vegetativas e reprodutivas foram caracterizadas segundo Radford et al. (1974) e Harris \& Harris (1994). A tipificação foliar foi baseada em Rizzini (1977), enquanto os padrões de venação e indumento fundamentaram-se em Hickey (1973) e Payne (1978), respectivamente. Os tipos de inflorescências foram verificados em Strasburger et al. (1974), Webberling (1995) e Rua (1999). As ilustrações foram confeccionadas através de câmara clara acoplada a estereomicroscópio. Os nomes populares foram obtidos, quando possível, nos rótulos das exsicatas ou, também, durante a execução dos trabalhos de campo.

\section{Resultados e discussão}

Euploca Nutt., Trans. Amer. Philos. Soc. 5: 137. 1837.

Hilgeria Förther, Sendtnera 5: 132. 1998.

Orthostachys (R. Br.) Spach, Hist. Nat. Vég. Phan. 9: 32. 1840.

Schleidenia Endl., Gen. Pl.: 646. 1839.

Ervas, subarbustos até arbustos, eretos a decumbentes, algumas vezes com xilopódios. Folhas alternas, subopostas, ou menos freqüentemente opostas ou espiraladas, pecioladas ou sésseis; lâmina membranácea, subcartácea, cartácea, subcarnosa ou subcoriácea, glabra ou indumentada; venação hifódroma ou, menos freqüentemente, broquidódroma. Inflorescência terminal, lateral ou internodal, com ou sem brácteas, solitária até 2-4 agrupadas, pedunculada, levemente a fortemente escorpióide, ou com flores solitárias, axilares ou supra-axilares. Flores sésseis, subsésseis ou longamente pediceladas; cálice 5-laciniado, parcialmente unido ou raramente livre, lacínios imbricados, geralmente desiguais entre si, com até três classes de tamanhos e diferentes formatos, persistente; corola 5-laciniada, tubular, tubular-hipocrateriforme ou campanulada, branca, com fauce amarela ou púrpura ou menos freqüentemente inteiramente amarela, margem ondulada ou ondulado-plicada, lacínios com distintos formatos, com apêndices ou não; estames 5, inclusos, epipétalos, alternos aos lacínios da corola, sésseis ou subsésseis, anteras dorsifixas, introrsas, conatas, ovadas, lanceoladas, ovado-lanceoladas ou lineares, pubescentes somente no ápice, apiculadas ou não, com glândulas ou não; ovário falsamente 4-locular pela intrusão de um septo, glabro ou indumentado, geralmente globoso ou com variações desse formato, óvulo 1 por lóculo; estilete presente ou ausente, algumas vezes inconspícuo, terminal, cilíndrico; estigma com diferentes formas, inteiro ou levemente bífido até tetráfido no ápice, persistente; disco nectarífero na base do ovário. Fruto esquizocárpico, núculas 4 com 1 semente cada. Sementes com embrião curvo.

Neste trabalho, admite-se a proposta de Hilger \& Diane (2003), sendo consideradas sob Euploca as espécies que apresentam fruto com quatro núculas, associadas às anteras conatas frequentemente com tricomas, flores geralmente com brácteas e embrião curvo. Também foram realizadas novas combinações das espécies que até o momento se encontravam circunscritas ao gênero Heliotropium e, estabelecidas novas espécies.

No Brasil foram encontradas 17 espécies, as quais são tratadas a seguir.

Epécie-tipo: Euploca convolvulacea Nutt.

Chave para as espécies

1. Flores solitárias, axilares ou supra-axilares, longamente pediceladas.

2. Corola sem apêndices.

3. Ramos vilosos; lacínios da corola ovados 5. E. humistrata

3. Ramos glabros ou pubérulos; lacínios da corola elípticos. 7. E. lagoensis

2. Corola com apêndices alternados com os lacínios.

4. Flores axilares; corola inteiramente amarela; fruto com arestas.... 10. E. paradoxa

4. Flores supra-axilares; corola com tubo amarelo, lacínios brancos; fruto sem arestas 11. E. parciflora

1. Flores reunidas em inflorescências, pediceladas, sésseis ou subsésseis.

5. Inflorescências abracteadas.

6. Corola 3,5-5,5 mm; anteras estreitamente lanceoladas; estigma de superfície cerdosa. 1. E. barbata

6. Corola 1,5-2 mm; anteras ovadas a ovado-lanceoladas; estigma de superfície pubescente 14.E. procumbens

5. Inflorescências bracteadas.

7. Pecíolo decorrente. 
8. Cálice com lacínios subcarnosos, alados; corola branca; ovário estipitado 15. E. rodaliae

8. Cálice com lacínios membranáceos, sem alas; corola amarela; ovário séssil 4. E. hassleriana 7. Pecíolo nunca decorrente.

9. Brácteas das inflorescências filiformes ou subuladas 2. E. filiformis

9. Brácteas das inflorescências com outros formatos.

10. Estilete ca. 0,3-1,5 mm.

11. Lâmina foliar estreitamente lanceolada ou oblanceolada; lacínios da corola ovadodeltóides. 12. E. polyphylla

11. Lâmina foliar ovada, elíptica, estreitamente elíptica, lanceolada a linear; lacínios da corola com outros formatos.

12. Brácteas lineares a estreitamente elípticas, inconspícuas; cálice nunca ultrapassando a porção mediana da corola 17. E. ternata

12. Brácteas elípticas ou lanceoladas, foliáceas; cálice de comprimento igual ou ligeiramente menor que a corola.

13. Lacínios da corola suborbiculares

16. E. salicoides

13. Lacínios da corola com outros formatos.

14. Lâmina foliar linear a lanceolada; estigma estreitamente cônico.

8. E. ocellata

14. Lâmina foliar elíptica; estigma cônico e variações desse formato.

15. Lacínios da corola ovado-elípticos

3. E. fruticosa

15. Lacínios da corola com outros formatos.

10. Estilete ca. $0,2 \mathrm{~mm}$ ou ausente.

16. Lâmina foliar estreitamente trulada a lanceolada, atenuada na base, margem revoluta.

9. E. pallescens

16. Lâmina foliar elíptica, base cuneada, margem não revoluta.

17. Corola 3-4 $\mathrm{mm}$; estigma espessado na base, levemente bífido no ápice, com superfície glabra 6. E. krapovickasii

17. Corola 4-7,5 mm; estigma delgado na base, 4-corniculado no ápice, com superfície cerdosa. 13. E. pottii

1. Euploca barbata (DC.) J.I.M.Melo \& Semir. Kew Bull. 64(2): 287. 2009. Heliotropium barbatum DC., Prodr. 9: 541. 1845. Tipo: Brasil, Bahia, ad Villan di Barra, Serra Jacobina, s.d., Blanchet 2726 (Holótipo: A. DC., fotografia!; Isótipo: K!).

Fig. 1: A-E

Erva, ca. $30 \mathrm{~cm}$, ereta ou decumbente, glauca. Ramos hirsutos. Folhas alternas, pecioladas; pecíolo 2-4 mm, viloso a tomentoso; lâmina 0,9-1,2x0,2-0,4 cm, subcarnosa, lanceolada a elíptico-lanceolada, ápice agudo, base atenuada, margem inteira, face adaxial serícea a vilosa, face abaxial tomentosa, indumento castanho; venação hifódroma. Inflorescência $0,5-1,5 \mathrm{~cm}$, terminal, abracteada; pedúnculo 0,5-1,5 cm. Flores 3,5-5,5 mm, sésseis; cálice $2 \mathrm{~mm}$, cerdoso, lacínios 2-2,2x0,2-0,3 mm, estreitamente lanceolados, cerdosos; corola $3,5-5,5 \mathrm{~mm}$, tubular, branca, fauce amarelo-alaranjado, tubo 3-3,5 mm, viloso externamente e internamente, lacínios 1-1,2 mm, subelípticos; estames subsésseis, filetes inseridos ca. 1,5 $\mathrm{mm}$ da base do tubo; anteras $1 \mathrm{~mm}$, estreitamente lanceoladas; ovário ca. $0,4 \mathrm{~mm}$, subgloboso, pubescente; estigma ca. $0,4 \mathrm{~mm}$, séssil, cônico, superfície cerdosa na região apical, disco basal espessado. Esquizocarpo ca. 1,5 mm diâm., globoso; núculas ca. 1,5 mm diâm., estrigosas. Sementes ca. 1 mm, elípticas.
Material examinado: BRASIL. Bahia: Flamengo, II/1968, fl. fr., Pontual 68/772 (PEUFR); Irecê, VIII/1980,

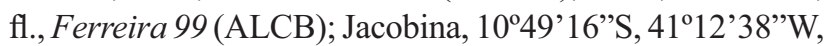
III/2004, fl. fr., Stapf et al. 243 (HUEFS, PEUFR); Santo Inácio, $11^{\circ} 01^{\prime} \mathrm{S}, 42^{\circ} 46^{\circ} \mathrm{W}, \mathrm{II} / 1977$, fl. fr., Harley 19076 (CEPEC, HRB, K, UEC); Xique-xique, $11^{\circ} 01^{\prime} 03^{\prime}$ 'S, 4245'48”W, VI/1996, fl., Guedes et al. (PCD) 3056 (ALCB, CEPEC, HUEFS, IBGE). Pernambuco: Petrolina, XI/1978, fl. fr., Leitão-Filho \& Timoni 8908 (UEC).

Espécie morfologicamente semelhante a $E$. procumbens, por compartilharem, principalmente, as inflorescências ebracteadas. Entretanto, distingue-se de E. procumbens por apresentar flores com ca. 5,5 mm, lacínios da corola subelípticos e, principalmente, pelo estigma com superfície cerdosa na região apical. Além disso, E. barbata ocorre apenas na Caatinga, enquanto que $E$. procumbens está associada a diferentes formações vegetacionais.

Até o presente, a espécie foi registrada apenas no Nordeste do Brasil, nos estados de Pernambuco e Bahia, sendo coletada pela primeira vez em Pernambuco. Está associada à vegetação de Caatinga, em várzeas, nas depressões residuais do rio São Francisco, habitando solo arenoso. A espécie é ilustrada pela primeira vez neste trabalho. Coletada com flores em fevereiro, março, junho, agosto e novembro e frutos em fevereiro, março e novembro. 
2. Euploca filiformis (Lehm.) J.I.M.Melo \& Semir, Kew Bull. 64(2): 288. 2009. Heliotropium filiforme Lehm., Gött. Gel. Anz. 3(152): 1515. 1817. Tipo: Venezuela, am Orinoko, s.d., Humboldt 1202 (Lectótipo: B, fotografia!).

Fig. 1: F-L

Erva ou subarbusto, ca. $25 \mathrm{~cm}$, ereto ou prostrado, glauco, ramificado, algumas vezes formando touceiras. Ramos cilíndricos, escabrosos a seríceos. Folhas alternas, pecioladas; pecíolo 0,1-0,4 cm, cilíndrico, nunca decorrente; lâmina 0,5-2,1x0,1-0,4 cm, membranácea, elíptica, lanceolada, oblanceolada ou, mais raramente, linear, ápice agudo, base atenuada, margem inteira, serícea a estrigosa em ambas as faces, com nervura proeminente, achatada; venação hifódroma. Inflorescência $0,8-9,5 \mathrm{~cm}$, terminal e lateral, sem pedúnculo; brácteas 1-1,2x0,3-0,4 $\mathrm{mm}$, filiformes a subuladas, opostas às flores, externamente e internamente glabrescentes. Flores 2,5-3 mm, subsésseis; cálice 2,3-2,8 $\mathrm{mm}$, quatro lacínios com 1,8-2,3×0,2-0,4 mm, ovados, um com 2-2,6x0,8-1 mm, elípticos a largamente elípticos, glabrescentes externamente e internamente; corola 2,3-3 mm, tubular, inflada, constricção na porção mediana, estrigosa externamente, glabrescente internamente, tubo 0,8-1,2 mm, lacínios 0,8-1,2 mm, estreitamente ovados; estames sésseis, inseridos entre 0,3-0,5 mm da base do tubo; anteras ca. 0,7 $\mathrm{mm}$, lanceoladas, apiculadas; ovário $0,3-0,5 \mathrm{~mm}$, subgloboso a globoso, disco nectarífero discreto; estigma ca. $0,3 \mathrm{~mm}$, séssil a subséssil, capitado, glanduloso na base. Esquizocarpo 1-1,5 mm diâm., globoso, sulcado; núculas ca. 1, $5 \mathrm{~mm}$ diâm., trígonas, seríceas. Sementes ca. 0,8 mm, elípticas.

Material selecionado examinado: BRASIL. Amazonas: Tefé, I/1974, fl. fr., PLK \& Eliana 12673 (INPA). Amapá: rio Araguari, X/1979, fl. fr., Austin et al. 7259 (MG); São Paulo, II/1950, fl. fr., Fróes 26036 (IAC). Bahia: Belmonte, 1552'S, 38 53'W, III/1974, fl. fr., Harley 17432 (CEPEC, IPA, K); Canavieiras, I/1965, fl. fr., Lana \& Castellanos 730 (CEPEC). Goiás: Niquelândia, $14^{\circ} 22^{\prime} 06^{\prime}$ 'S, 48²5'54”W, XII/1996, fl. fr., Azevedo et al. 1120 (BAB, IBGE, RB, US); Posse, II/1990, fl. fr., Arbo et al. 3533 (CTES, HRCB). Maranhão: Santa Inês, XII/1978, fl. fr., Rosa \& Vilar 2988 (MG). Mato Grosso: Barra do Bugres, 1509'41"S, IV/2005, fl. fr., Stapf et al. 410 (HUEFS, PEUFR); Chapada dos Guimarães, III/1983, fl. fr., Lisboa et al. 3269 (MG); Cuiabá, I/1986, fl. fr., Miranda 31 (CH); Igarapezinho, $59^{\circ} 21^{\prime} \mathrm{S}, 10^{\circ} 12^{\prime} \mathrm{W}, \mathrm{X} / 1973$, fl. fr., Berg et al. s/n (R P18416); Poconé, XI/2002, fl. fr., Melo \&

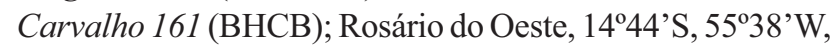
X/1997, fl. fr., Souza et al. 20770 (UEC); Santo Antonio do Levérger, 1545'11''S, 56 04'17'W, X/1978, fl. fr., Duarte \& Assumpção 926 (UEC, UFMT); Vila Bela da Santíssima Trindade, XI/1996, fl. fr., Hatschbach \& Silva 65498 (MBM, UFP). Mato Grosso do Sul: Aquidauana, 19²9'S, 56 $23^{\circ} \mathrm{W}$, s/d, fl. fr., Pott et al. 5765 (COR, PEUFR); Brasilândia, 214'51"S, 5207'54”W, IX/1996, fl. fr., Pietrobom-Silva 3499 (IPA, SJRP); Corumbá, 1859’S, 56³9’W, X/1984, fl., fr. Pott 1645 (COR, CTES, PEUFR); Dourados, II/1975, fl. fr., Pedersen 11089 (CTES); Porto Murtinho, X/2003, fl. fr., Hatschbach et al. 76535 et al. (MBM); rio Negro, 19²1'48”'S, 54 59'35”'W, VIII/1998, fl. fr., Pott et al. 3536 (COR, PEUFR). Minas Gerais: Jaboticatubas, III/1987, fl. fr., Vieira \& Reis 570 (VIC); Santana do Riacho, XI/2000, fl. fr., Kinoshita \& Barbosa 593 (HST, UEC). Pará: Altamira, XI/1986, fl. fr., Dias et al. 614 (MG); Itaituba, XI/1999, fl. fr., Lisboa et al. 6796 (MG); Itupiranga, X/1977, fl. fr., Berg \& Henderson BG647 (MG); Marabá, VIII/1984, fl. fr., Rosa et al. 4622 (MG); Pindobal, s/d, fl., Black 47-1924 (IAC); Santarém, XII/1978, fl. fr., Maciel \& Cordeiro 110 (MG); Senador José Porfírio, X/1985, fl. fr., Almeida 381 (MG). Rio de Janeiro: Campos dos Goytacazes, I/1940, fl. fr., Sampaio 8756 (R). Rondônia: Estrada Porto Velho-Cuiabá, VII/1983, fl. fr., Miranda et al. s/n (MG 124292); Guajará-Mirim, I/1983, fl. fr., Carreira et al. 314 (HRB, INPA); Porto Velho, XII/1940, fl. fr., Xavier s/n (PEUFR 34924, JPB 0044). Roraima: Normandia, V/1995, fl. fr., Miranda 730 (INPA); Rio Arraia, VI/1974, fl. fr., Pires \& Leite 14728 (MG). São Paulo: Estreito, XI/1997, fl. fr., Marcondes-Ferreira et al. 1540 (HRCB, UEC); Monte Alto, XI/1995, fl. fr., Bernacci 2171 (UEC); Presidente Epitácio, XI/1992, fl. fr., Cordeiro et al. 1142 (CH); Rifania, IV/1981, fl. fr., Leitão-Filho et al. 12500 (UEC); São Carlos-Ribeirão Preto, IX/1968, fl. fr., Aranha 29 (SJRP). Tocantins: Miracema do Tocantins, 48²3'18'S, 0944'53”'W, XII/1998, fl. fr., Árbocz 6273 (IBGE); Porto Nacional, 1090'88'S, 48 51'00”'W, XII/1991, fl. fr., Lira \& Noleto 07 (HTINS, IBGE); Remansão, IX/1948, fl. fr., Froes 23465 (CTES); Rio Tocantins, XII/1979, fl. fr., Silva et al. 119 (MG).

Material adicional examinado: ARGENTINA. Corrientes: Dept $^{\circ}$. Santo Tomé, III/1983, fl. fr., Cristóbal et al. 1916 (CTES, MBM). BOLÍVIA. Pando: Sul do Rio Abunã, XI/1968, fl. fr., Prance et al. 8572 (MG, R). URUGUAI. Dept $^{\circ}$ Artigas: Cuchilla Yacaré Cururu, IV/1997, fl. fr., Pedersen 16291 (C, MBM). VENEZUELA. Amazonas: Cano Cataniapo, V/1977, fl. fr., Steyermark \& Huber 113874 (VEN); Dept $^{\circ}$. Rio Negro, San Carlos de Rio Negro, $01^{\circ} 50^{\prime} \mathrm{N}, 66^{\circ} 55^{\prime} \mathrm{W}$, s/d, fl. fr., Stergios \& Aymaiel 9343 (PORT, VEN); Puerto Ayacucho, XI/1977, fl. fr., Morillo 6705 (VEN). Apure: Distrito Muñoz, 07³1'N, 6936’W, V/1990, fl. fr., Gómez \& Ramia 851 (VEN); Distrito Pedro Camejo, V/1977, fl. fr., Davidse \& Gonzélez 12882 (MO, VEN). Bolívar: Aripao, 06²1'55'N, 6445'45”W, III/1995, fl. fr., Rosales et al. 1469 (VEN); Distrito Paez, La Grulla, VII/1978, fl. fr., Delascio \& Liesner 6803 (VEN).

Espécie morfologicamente relacionada a E. barbata e E. procumbens, especialmente no aspecto geral. Entretanto, distinguiu-se de ambas as espécies pela presença de brácteas na inflorescência, essas filiformes a subuladas, pela lâmina foliar, que varia desde elíptica, lanceolada, oblanceolada a linear, com base atenuada e, principalmente, pelo estigma glanduloso na base.

Distribui-se desde o México, Antilhas, alcançando Argentina (Frohlich 1978) e, no Brasil, nas regiões Norte (AM, AP, PA, RO, RR, TO), Nordeste (BA, MA), Centro-Oeste (GO, MT, MS) e Sudeste (MG, RJ, SP). É registrada pela 
primeira vez na região Nordeste, e nos estados do Amapá, Rondônia, Roraima, Tocantins e Mato Grosso do Sul. Geralmente é encontrada próxima a cursos d'água e em áreas sujeitas a inundações periódicas, especialmente em leitos de rios e lagos na planície amazônica, depressão pantaneira, Cerrado e em ecótono Cerrado-Campo rupestre (SP), associada a solos arenosos, argilosos ou areno-argilosos, em altitudes até $820 \mathrm{~m}$. Coletada com flores e frutos todo o ano.

3. Euploca fruticosa (L.) J.I.M.Melo \& Semir, Kew Bull. 64(2): 288. 2009. Heliotropium fruticosum L., Syst. Nat. 10: 913. 1759. Tipótipo: Jamaica, Sloane, tab. 132, fig. 4, (BM, fotografia!).

Fig. 1: M-Q

Erva ou subarbusto, $20-50 \mathrm{~cm}$, ereto ou prostrado; xilopódio presente ou não. Ramos subcilíndricos a cilíndricos, levemente a fortemente sulcados, estrigosos, alternados por indumento viloso a hirsuto, tricomas lustrosos, alvos ou ferrugíneos apenas na porção inferior ou até $2 / 3$ destes. Folhas alternas, sésseis ou pecioladas; pecíolo 1-4 mm, achatado, pubérulo, nunca decorrente, tricomas ferrugíneos; lâmina 1-3,9x0,3-1,2 cm, membranácea, estreitamente elíptica a elíptica, lanceolada ou mais raramente ovada, ápice agudo, algumas vezes apiculado, base subtruncada a atenuada, margem inteira a levemente sinuada, plana a levemente revoluta, face adaxial vilosa, face abaxial serícea, ambas com tricomas ferrugíneos; venação broquidódroma. Inflorescência 1-8,3 $\mathrm{cm}$, terminal ou lateral; pedúnculo $1,3-4,5 \mathrm{~cm}$; brácteas 0,3-1,1 x0,1-0,4 cm, foliáceas, elípticas, estreitamente elípticas a ovadas, externamente glabrescentes, internamente pubérulas a estrigosas. Flores 6-7 mm, subsésseis; cálice 4-6 $\mathrm{mm}$, apresentando três classes de tamanho, das quais quatro lacínios apresentam duas classes de tamanho, os menores (3) 3,8-5,2x0,7-0,8 mm e o maior (1) 4-6x0,8-1 mm, e (1) 3-4,2x0,7-0,8 mm, lanceolados, ovado-lanceolados, vilosos ou não, margem ciliada; corola 6-7 mm, tubular, branca, fauce amarela, externamente estrigosa, internamente vilosa, tubo 3,5-4 mm, lacínios 2-2,7 mm, ovado-elípticos; estames subsésseis, filetes inseridos ca. $2 \mathrm{~mm}$ da base do tubo; anteras ca. $1 \mathrm{~mm}$, ovadas, apiculadas; ovário ca. $0,5 \mathrm{~mm}$, globoso, disco nectarífero espessado, enegrecido; estilete 1,3-1,5 mm; estigma 0,8-1 mm, cônico a largamente cônico. Esquizocarpo ca. 2 mm diâm., depresso-globoso; núculas ca. $2 \mathrm{~mm}$ diâm., ventralmente fendidas, pubérulas, com uma cavidade amarronzada na região ventral. Sementes ca. 1,5 mm, elípticas.

Material selecionado examinado: BRASIL. Bahia: Caetité, VIII/1993, fl. fr., Guedes s/n (ALCB 26290); Dom Basílio, XII/1989, fl. fr., Carvalho et al. 2683 (CEPEC); Morro do Chapéu, III/1997, fl. fr., Lughadha et al. 5994 (ALCB, HUEFS, SPF).

Material adicional examinado: VENEZUELA. Aragua: Distrito Girardot, via Ocumare de la Costa, $10^{\circ} 28^{\prime} \mathrm{N}$, 6746’W, XI/1983, fl., Rodriguez 117 (VEN). Falcón: Distrito Silva, Caño Ramadita, IX/1974, fl., Steyermark \&
Manara 110513 (VEN). Sucre: Península de Araya, Cariaco, 10³8’N, 6340’W, V/1981, fl. fr., Liesner \& González 11947 (MO, VEN).

Euploca fruticosa é morfologicamente relacionada à E. salicoides e E. ternata, com as quais compartilha, principalmente, a presença de estilete. Entretanto, é reconhecida facilmente por apresentar lâmina foliar elíptica, inflorescências com brácteas foliáceas, elípticas ou lanceoladas, flores com 6-7 mm e, pelos lacínios da corola ovado-elípticos.

Ocorre do sul dos Estados Unidos e Antilhas, alcançando Venezuela até o Brasil. No Brasil, a espécie foi encontrada, até o momento, apenas no estado da Bahia, em vegetação de Caatinga provavelmente devido à escassez de coletas. Johnston (1928) registrou-a para o Piauí, no entanto, nesse trabalho não foi encontrada naquele Estado. Coletada florida e frutificada em março, agosto e dezembro.

4. Euploca hassleriana (Chodat) J.I.M.Melo \& Semir, Kew Bull. 64(2): 288. 2009. Heliotropium hasslerianum Chodat, Bull. Herb. Boissier 2: 817. 1902. Tipo: Paraguai, Sierra de Maracayú, in regione vicine Igatimi, s.d., Hassler 4761 (Holótipo: GH!; K!).

Fig. 2: A-E

Subarbusto, ca. 25 cm, ereto; xilopódio presente ou não. Ramos difusos, estrigosos a escabrosos, com revestimento semelhante a ritidoma desprendendo-se em longas faixas longitudinais. Folhas alternas, pecioladas; pecíolo 1-2 mm, estrigoso, decorrente; lâmina 1,2-2,5x0,5-1,25 cm, membranácea, elíptica, lanceolada a ovada, ápice mucronado a agudo, margem inteira, levemente revoluta, ciliada, base atenuada, geralmente estrigosa, com tricomas, na maioria, ferrugíneos, algumas vezes glabrescente, em ambas as faces; venação broquidódroma, nervura central impressa na face adaxial, proeminente na face abaxial. Inflorescência 1,4-2,5 $\mathrm{cm}$, terminal, solitária ou dicótoma, congesta; pedúnculo 0,6-1 cm; brácteas $0,7-1,1 \times 0,25-0,4 \mathrm{~cm}$, foliáceas, elípticas a ovadas, pubescentes externamente e internamente. Flores 5-8 mm, sésseis; cálice 4-6 mm, lacínios membranáceos, com duas classes de tamanho (3) 4-6x0,8-1 mm, (2) 3,7-5,5x0,7$1 \mathrm{~mm}$, ovado-lanceolados, pubescentes externamente e internamente; corola 6-6,8 mm, tubular, amarela, estrigosa externamente, vilosa internamente, especialmente na altura da fauce e estames, tubo ca. $5 \mathrm{~mm}$, constricção ca. 3,2 mm da base do tubo, lacínios 1,8-2 mm, largamente elípticos, involutos; estames subsésseis, filetes inseridos ca. $2 \mathrm{~mm}$ da base do tubo; anteras ca. $1 \mathrm{~mm}$, estreitamente ovadas, base levemente cordada, ápice discretamente caudado; ovário ca. 0,5 mm, séssil, globoso, pubescente; estilete ca. 0,8 $\mathrm{mm}$; estigma ca. $0,7 \mathrm{~mm}$, cônico, porção estéril espessada, pubescente ou glabrescente no ápice. Esquizocarpo 2-2,5 mm diâm.; núculas ca. 2 mm diâm., trígonas, pubescentes, com cicatriz na face ventral. Sementes ca. 1,5 mm, elípticas. 


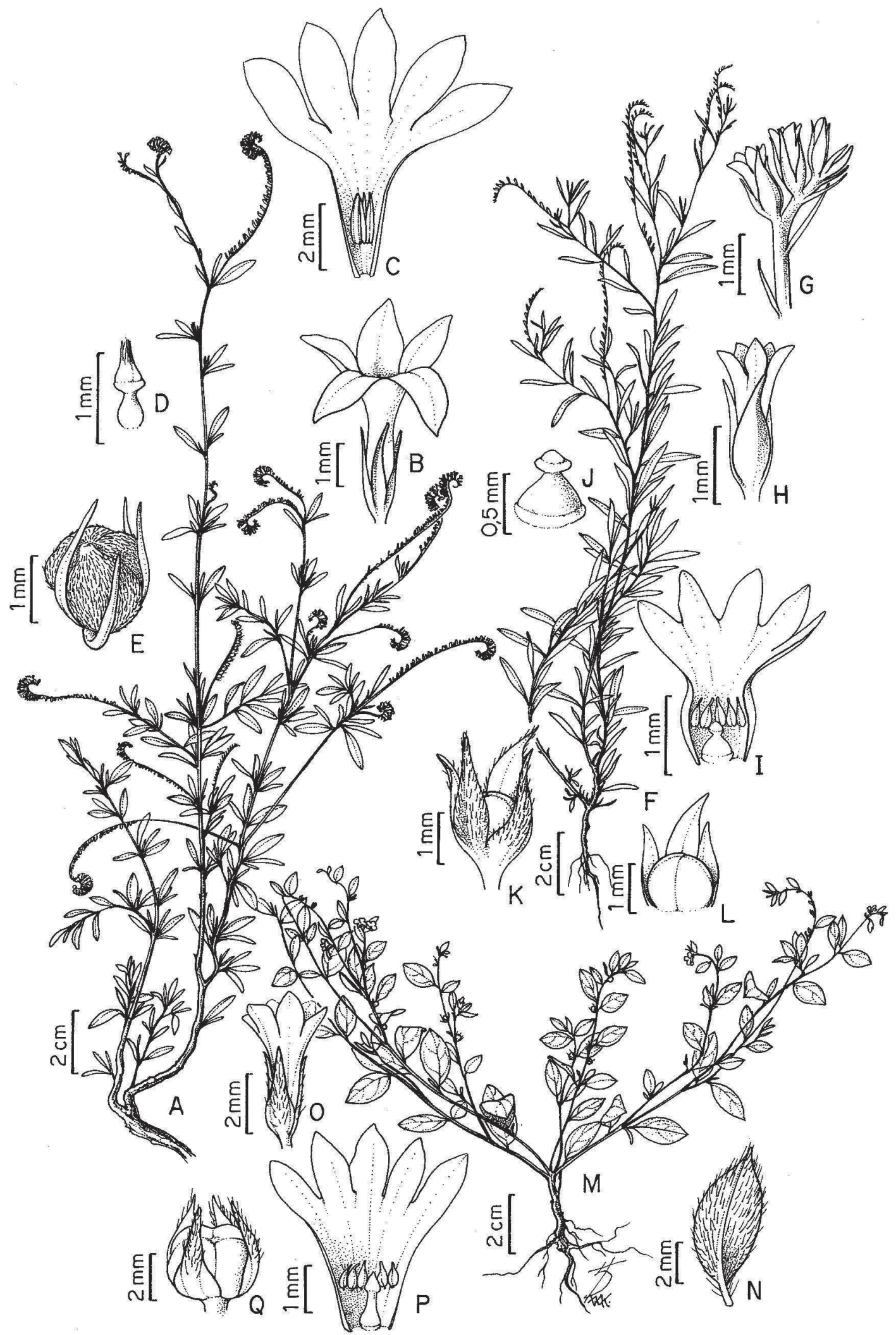

Figura 1. A-Q. Euploca barbata (DC.) J.I.M.Melo \& Semir (Harley 19076): A. Ramo reprodutivo. B. Flor. C. Corola rebatida, evidenciando androceu. D. Gineceu. E. Fruto, em vista lateral (Stapf 243). E. filiformis (Lehm.) J.I.M.Melo \& Semir (Marcondes-Ferreira et al. 1540): F. Ramo reprodutivo. G. Detalhe da inflorescência, evidenciando a bráctea. H. Flor. I. Corola rebatida, evidenciando androceu e gineceu. J. Gineceu. K. Fruto, evidenciando cálice acrescente. L. Fruto, em vista lateral. E. fruticosa (L.) J.I.M.Melo \& Semir (Guedes s/n ALCB 26290): M. Hábito. N. Bráctea. O. Flor. P. Corola rebatida, evidenciando androceu e gineceu. Q. Fruto, em vista lateral. 
Material examinado: BRASIL. Mato Grosso do Sul: Amambaí, X/1984, fl. fr., Hatschbach \& Kummrov 48440 (MBM); Rio Brilhante, X/1970, fl., Hatschbach 25200 (MBM).

Esta espécie é morfologicamente relacionada à E. rodaliae, por compartilharem, especialmente, a base da lâmina foliar com pecíolo decorrente. É reconhecida facilmente pelos lacínios do cálice membranáceos, desprovidos de alas, pela corola amarela com lacínios involutos e pelo ovário sem estípete. Além disso, ambas as espécies apresentam distribuição geográfica distinta; E. hassleriana restringe-se à região Centro-Oeste, enquanto que $E$. rodaliae dispersa-se na região Nordeste.

Distribui-se no Paraguai, Argentina e, no Brasil, no Mato Grosso do Sul. Ocorre associada à vegetação de cerrado, em campo limpo. Coletada com flores e frutos em outubro, sobre afloramento rochoso.

5. Euploca humistrata (Cham.) J.I.M.Melo \& Semir, Kew Bull. 64(2): 288. 2009. Heliotropium humistratum Cham., Linnaea 4: 462. 1829. Tipo: Brasil, Minas Gerais, Fazenda de Piedade, s.d., Sellow 1578/ 673 (Holótipo: $\mathrm{GH}$, fragmento e fotografia!; $\mathrm{K}$ !).

Fig 2: F-I

Erva, prostrada. Ramos cilíndricos, estriados, vilosos, tricomas hialinos levemente a fortemente ferrugíneos, principalmente na região nodal. Folhas alternas, congestas somente no ápice dos ramos, pecioladas; pecíolo levemente sulcado; lâmina 5-8x1,5-2 mm, subcarnosa, lanceolada, ápice agudo, base atenuada, margem inteira, vilosa na face adaxial e na face abaxial, às vezes com tricomas de base dilatada apenas na face adaxial; venação hifódroma. Flores 2,5-3 mm, solitárias, supra-axilares, longamente pediceladas; pedicelo 1-1,5 mm; cálice 2,3-2,8 mm, lacínios 2,2-2,7x 0,4-0,5 mm, lanceolados, externamente e internamente pubérulos, tricomas aciculares, hialinos, alvos; corola $3 \mathrm{~mm}$, sem apêndices, tubular, branca, externamente estrigosa, internamente pubescente, tubo ca. 1,8 mm, lacínios 1-x0,5-0,6 $\mathrm{mm}$, ovados; estames sésseis, inseridos ca. $0,7 \mathrm{~mm}$ da base do tubo, posicionados acima do ápice estigmático; anteras $0,7 \mathrm{~mm}$, ovadas, discretamente apiculadas; ovário ca. 0,3 $\mathrm{mm}$, globoso, sulcado; estigma $1,5 \mathrm{~mm}$, séssil, largamente cônico, fortemente achatado na base. Esquizocarpo ca. 1,5 $\mathrm{mm}$ diâm., subgloboso, rostrado; núculas $0,8 \mathrm{~mm}$ diâm., trígonas, glabras; pedicelo 1,2-2 mm. Sementes ca. 1,2 mm, oblongo-elípticas.

Material examinado: BRASIL. Goiás: Manoel Alves, X/1839, fl., Gardner 3359 (K). Minas Gerais: Arcos, II/1940, fl. fr., Oliveira 239 (BHCB, BHMH); entre Ouro Preto e Mariana, s/d, fl., Glaziou 13822 (K).

Euploca humistrata é morfologicamente relacionada à $E$. paradoxa, por apresentarem, principalmente, ramos vilosos com flores solitárias, longamente pediceladas. Entretanto, é reconhecida, especialmente, pelas flores axilares, corola tu- bular, estames inseridos acima do ápice estigmático, estigma ca. 1,5 mm, largamente cônico, séssil e, pelo ovário globoso.

Ocorre apenas no Brasil, no estado de Minas Gerais, associada à vegetação de cerrado e foi registrada por Johnston (1928) em Goiás, no Brasil Central e, o único exemplar obtido nesse Estado encontra-se depositado em Kew. A última coleta foi feita em 1940, em Minas Gerais e, por esta razão, presume-se que E. humistrata tenha sido extinta. Coletada com flores em fevereiro e outubro, e com frutos em fevereiro.

6. Euploca krapovickasii J.I.M.Melo \& Semir, Kew Bull. 64(2): 288. 2009. Tipo: Brasil, Alegrete, I/1973, Krapovickas et al. 22780 (Holótipo: CTES!).

Fig. 2: J-N

Erva, ca. $15 \mathrm{~cm}$, subdecumbente. Ramos difusos, sulcados, estrigosos a densamente estrigosos, especialmente na região terminal das partes jovens, tricomas esbranquiçados. Folhas alternas, congestas, pecioladas; pecíolo $0,35-0,5 \mathrm{~mm}$, achatado, dorsalmente sulcado, viloso a tomentoso, nunca decorrente; lâmina 1,5-2 x 0,45-0,5 cm, membranácea, elíptica, levemente discolor, ápice agudo, margem inteira, não revoluta, base cuneada, estrigosa em ambas as faces; venação broquidódroma. Inflorescência 0,6-2,3 cm, terminal, levemente escorpióide, pauciflora; brácteas 3-3,5 x 0,7-1 $\mathrm{mm}$, elípticas, vilosas externamente e internamente, margem ciliada. Flores 3,8-4 mm, subsésseis; cálice geralmente ultrapassando o tubo da corola, lacínios com três classes de tamanho, os menores 2-2,3 x 0,8 mm, o intermediário 3,2 x $0,5 \mathrm{~mm}$, os maiores $3,7 \times 0,8 \mathrm{~mm}$, lanceolados, discolores, com alas hialinas, vilosos externamente, inclusive nas margens, glabros internamente; corola ca. $3,4 \mathrm{~mm}$, tubular, branca, vilosa externamente, pubescente internamente apenas na região do tubo, constricção ca. $1,5 \mathrm{~mm}$ da base do tubo, tubo ca. $2 \mathrm{~mm}$, lacínios ca. $1 \mathrm{~mm}$, ligulados; estames subsésseis, filetes inseridos ca. 0,5 $\mathrm{mm}$ da base do tubo; anteras $0,8-1 \mathrm{~mm}$, ovado-triangulares, longo apiculadas; ovário ca. $0,6 \mathrm{~mm}$, globoso, com disco nectarífero discreto; estigma ca. $0,3 \mathrm{~mm}$, porção estéril espessada, porção fértil cônica, levemente bífida no ápice, glabro. Esquizocarpo ca. 1,7 mm diâm., globoso; núculas ca. 1,5 mm diâm., trígonas, pubérulas, faces ventrais com cicatriz crateriforme na região central. Sementes ca. 1,2 mm, largamente elípticas.

Material examinado: BRASIL. Rio Grande do Sul: Alegrete, I/1973, fl. fr., Krapovickas et al. 22780 (CTES).

Euploca krapovickasii é morfologicamente semelhante à E. ocellata, as quais compartilham as inflorescências terminais, paucifloras, com brácteas foliáceas. Entretanto, a espécie é reconhecida facilmente pelas brácteas com ca. 3,5 $\mathrm{mm}$, lacínios da corola ligulados, anteras ovado-triangulares ou, ainda, pelo estigma cônico. Foi coletada apenas uma vez no Brasil, em campo pedregoso.

7. Euploca lagoensis (Warm.) Diane \& Hilger, Bot. Jahrb. Syst. 125(1): 48. 2003. Tipo: Brasil, Minas Gerais, ad 


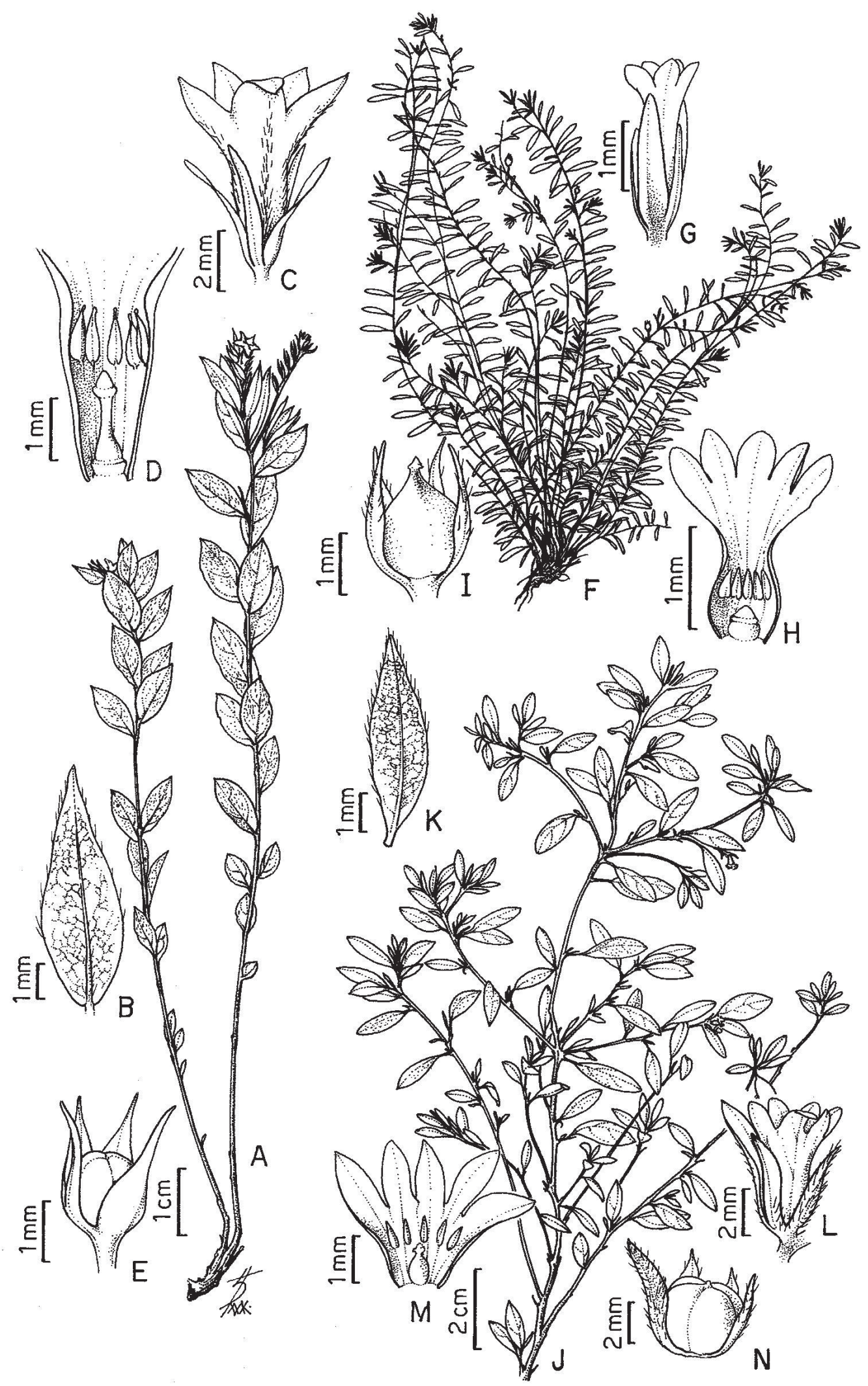

Figura 2. A-N. Euploca hassleriana (Chodat) J.I.M.Melo \& Semir (Hatschbach \& Kummrov 48440): A. Ramo reprodutivo, com detalhe do indumento. B. Bráctea. C. Flor. D. Corola rebatida, evidenciando androceu e gineceu. E. Fruto, em vista lateral. E. humistrata (Cham.) J.I.M.Melo \& Semir (Oliveira 239): F. Ramo reprodutivo. G. Flor. H. Corola rebatida, evidenciando androceu e gineceu. I. Fruto, em vista lateral. E. krapovickasii J.I.M.Melo \& Semir (Krapovickas et al. 22780): J. Ramo reprodutivo. K. Bráctea. L. Flor. M. Corola rebatida, evidenciando androceu e gineceu. N. Fruto, em vista lateral. 
Lagoa Santa ad ripam lacus vulgaris, in solo tempore pluviali inundato, XI/1864, Warming s.n. (Holótipo: M, fotografia!; $\mathrm{GH}$, fragmento!).

Fig. 3: A-D

Erva, ca. $10 \mathrm{~cm}$, decumbente ou prostrada, glauca. Ramos glabros ou, mais raramente, pubérulos. Folhas alternas, pecioladas; pecíolo ca. $1 \mathrm{~mm}$, subcilíndrico, glabro; lâmina 0,5-0,9x0,1-0,2 cm, membranácea a subcarnosa, estreitamente elíptica a oblongo-elíptica, ápice agudo ou acuminado, base atenuada, margem inteira, ciliada, face adaxial glabra, face abaxial glabra a pubérula; venação hifódroma. Flores ca. $3 \mathrm{~mm}$, solitárias, supra-axilares, longamente pediceladas; pedicelo ca. $0,5 \mathrm{~mm}$; cálice parcialmente unido, lacínios 2-2,8x0,4-0,5 mm, ovados a largamente ovados, pubérulos externamente e internamente; corola 3-4 mm, sem apêndices, tubular, branca, fauce amarela, externamente e internamente pubérula, tubo ca. $2 \mathrm{~mm}$, lacínios 0,8-1 mm, elípticos; estames sésseis, inseridos ca. $0,5 \mathrm{~mm}$ da base do tubo; anteras 0,6 $\mathrm{mm}$, ovadas; ovário ca. $0,5 \mathrm{~mm}$, subgloboso; estigma ca. 0,3 mm, subséssil, cônico, disco basal espessado. Esquizocarpo ca. 2 mm diâm., piriforme, sulcado, rostrado; núculas ca. 1,5 $\mathrm{mm}$ diâm., trígonas, glabras; pedicelo 2-2,5 mm, glabro ou pubérulo. Sementes 1-1,2 mm, elípticas.

Material selecionado examinado: BRASIL. Amazonas: Alto Amazonas, 1875, fl. fr., Traill 571 (K). Ceará: Aiuaba, III/1991, fl. fr., Figueiredo et al. 26 (EAC, MOSS); Morada Nova, IV/1997, fl. fr., Castro s/n (EAC 24899, HST 12067). Goiás: Teresina de Goiás, 13³0'S, 47³0’ W, XI/1996, fl. fr., Pereira \& Brancarenga 3311 (IBGE, RB, UEC, US). Mato Grosso do Sul: Corumbá, 1859’S, 56³9’ W, X/1998, fl. fr., Pott et al. 3762 (CPAP). Minas Gerais: Formoso, 1509'40"S, 4545'42”W, XII/1997, fl. fr., Silva 3748 (IBGE, US). Paraíba: Patos, IV/1971, fl. fr., Miranda \& Moura 117 (JPB). Piauí: Campo Maior, III/1968, fl. fr., Lima 68-5335 (IPA); Floriano, IV/2005, fl. fr., Miranda et al. 5035 (HST). Rio Grande do Norte: Serra Negra do Norte, V/2005, fl. fr., Queiroz 285 (PEUFR, UFRN). São Paulo: Itirapina, II/1984, fl. fr., Leitão-Filho et al. 15968 (HRCB, UEC); São Paulo, XII/1962, fl. fr., Lima 62-4135 (IPA).

Material adicional examinado: VENEZUELA. Apure: Mantecal, V/1971, fl. fr., Ramia 4367 (VEN). Cojedes: San Carlos, IV/1925, fl., Pittier 11703 (VEN).

Euploca lagoensis é reconhecida facilmente pelos ramos glabros ou menos freqüentemente pubérulos, com flores supra-axilares, estas com ca. $3 \mathrm{~mm}$, lacínios da corola elípticos e pelos frutos piriformes, rostrados.

Distribui-se desde o México, incluindo Antilhas, alcançando o Brasil, nas regiões Norte (AM), Nordeste (CE, PB, PI), Centro-Oeste (GO, MS) e Sudeste (MG, SP). É referida pela primeira vez para as regiões Nordeste e Centro-Oeste. Está associada à Caatinga, Cerrado, ambientes de transição Caatinga-Cerrado, depressão pantaneira ou, ainda, na Floresta Amazônica; em margens de rios e lagoas, leitos secos de lagoas temporárias e áreas sujeitas a inundações periódicas, geralmente formando densas populações. Coletada com flores e frutos entre fevereiro e maio, e de outubro a dezembro.

8. Euploca ocellata (Cham.) J.I.M.Melo \& Semir, Kew Bull. 64(2): 285. 2009. Heliotropium ocellatum Cham., Linnaea 4: 463. 1829. Tipo: Brasil meridional, s.l., s.d., Sellow 3579 (Isótipo: B, GH, fragmento, fotografia!).

Fig. 3: E-I

Erva, ca. $8 \mathrm{~cm}$, decumbente. Ramos estrigosos. Folhas alternas, pecioladas; pecíolo $0,1-0,3 \mathrm{~cm}$, estrigoso, nunca decorrente; lâmina 0,8-1,2x0,1-0,3 cm, subcartácea, linear a lanceolada, ápice agudo, margem revoluta, base cuneada, estrigosa em ambas as faces; venação hifódroma. Inflorescência $0,5-3 \mathrm{~cm}$, terminal, pauciflora; pedúnculo 0,3-1,3 $\mathrm{cm}$; brácteas 4-6,2×1-1,6 mm, foliáceas, lanceoladas, glabras externamente, pubérulas internamente. Flores ca. $3,5 \mathrm{~mm}$, subsésseis; cálice ca. $3 \mathrm{~mm}$, lacínios com duas classes de tamanhos, os menores (3) com 2-2,2x0,5 mm, os maiores (2) com $3 \times 0,6 \mathrm{~mm}$, lanceolados, estrigosos externamente, glabros internamente; corola ca. $3 \mathrm{~mm}$, tubular, branca, tubo ca. $2 \mathrm{~mm}$, lacínios ca. 1,5 mm, estreitamente elípticos; estames subsésseis, filetes inseridos ca. $0,7 \mathrm{~mm}$ da base do tubo; anteras ca. $0,7 \mathrm{~mm}$, ovadas; ovário ca. 0,5 mm, globoso, glabrescente; estigma ca. 0,4 $\mathrm{mm}$, subséssil, estreitamente cônico. Esquizocarpo ca. 2 mm diâm., globoso; núculas ca. 1,5 mm diâm., trígonas, seríceas. Sementes ca. $1 \mathrm{~mm}$, elípticas.

Material examinado: BRASIL. Rio Grande do Sul: Quaraí, I/1997, fl. fr., Pedersen 11664 (HST).

Espécie morfologicamente relacionada à E.a frutico$s a$, com a qual compartilha, especialmente, as brácteas foliáceas. Entretanto, é reconhecida facilmente pelas inflorescências paucifloras, flores com ca. $3,5 \mathrm{~mm}$, lacínios da corola com ca. $1,5 \mathrm{~mm}$, estreitamente elípticos, estigma estreitamente cônico e, também, pela distribuição restrita à região Sul.

Ocorre na Argentina e, no Brasil, foi encontrada, até o momento, no Rio Grande do Sul. Coletada com flores e frutos em janeiro.

9. Euploca pallescens (I.M. Johnst.) J.I.M.Melo \& Semir, Kew Bull. 64(2): 289. 2009. Heliotropium pallescens I.M. Johnst., Contr. Gray Herb. 81: 65. 1928. Tipo: Paraguai, Loma Clavel, Gran Chaco, XI/1903, Hassler 2477 (Holótipo: GH, fotografia!).

Fig. 3: J-N

Erva, ca. $30 \mathrm{~cm}$, ereta, subereta ou prostrada. Ramos cilíndricos, difusos, seríceos, amarelo-esverdeados. Folhas alternas ou subopostas, pecioladas; pecíolo $0,1-4,5 \mathrm{~cm}$, nunca decorrente; lâmina 1-4,5x0,1-0,5 cm, membranácea, estreitamente trulada a lanceolada, ápice acuminado a agudo, base atenuada, margem levemente a fortemente revoluta, ciliada, face adaxial e abaxial serícea, tricomas lustrosos; venação hifódroma. Inflorescência $0,6-13,8 \mathrm{~cm}$, terminal 


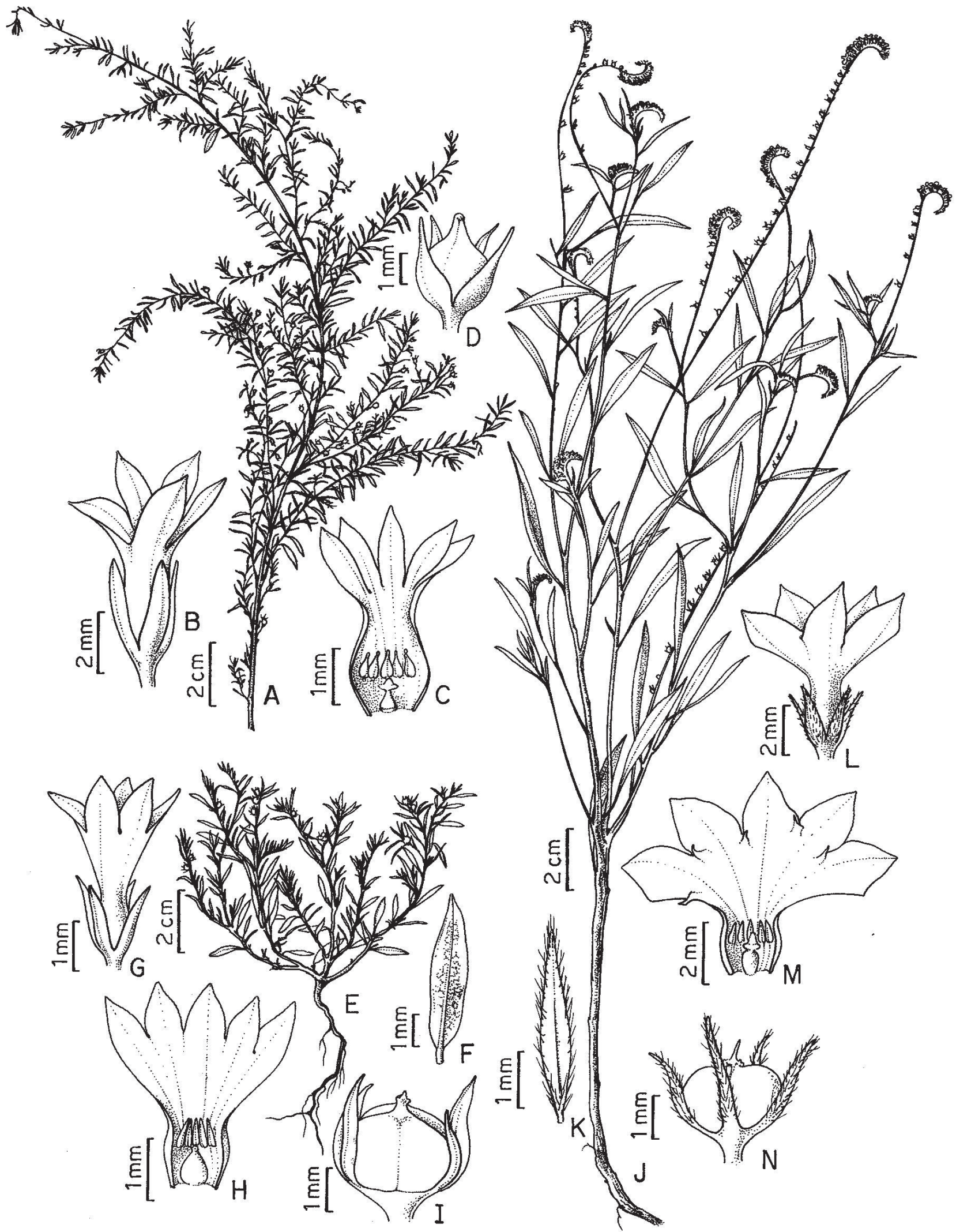

Figura 3. A-N. Euploca lagoensis (Warm.) Diane \& Hilger (Miranda et al. 5035): A. Ramo reprodutivo. B. Flor. C. Corola rebatida, evidenciando androceu e gineceu. D. Fruto, em vista lateral. E. ocellata (Cham.) J.I.M.Melo \& Semir (Pedersen 11664): E. Ramo reprodutivo. F. Bráctea. G. Flor. H. Corola rebatida, evidenciando androceu e gineceu. I. Fruto, em vista lateral. E. pallescens (I.M. Johnst.) J.I.M.Melo \& Semir (Silva 06): J. Ramo reprodutivo. K. Bráctea. L. Flor. M. Corola rebatida, evidenciando androceu e gineceu. N. Fruto, em vista lateral. 
e axilar; pedúnculo $0,2-4,8 \mathrm{~cm}$; brácteas $2-4 \times 0,5 \mathrm{~mm}$, estreitamente elípticas, foliáceas, estrigosas, margem ciliada; laxa ou congesta apenas na região apical. Flores 4,2-6,2 $\mathrm{mm}$, subsésseis; cálice 2,4-3 mm, lacínios 2-2,3×0,5-0,8 $\mathrm{mm}$, elípticos, livres, disjuntos, pubérulos externamente; corola 4-6 mm, campanulada, branca, tubo 2-3 mm, lacínios 2-2,5x1-2 mm, obovados a largamente deltados; estames sésseis, inseridos ca. $0,8 \mathrm{~mm}$ da base do tubo; anteras ca. 1 $\mathrm{mm}$, estreitamente ovadas, ápice apiculado; ovário ca. 0,3 $\mathrm{mm}$, ligeiramente botuliforme; estilete ca. $0,2 \mathrm{~mm}$ ou ausente; estigma $0,5 \mathrm{~mm}$, séssil, estreitamente cônico, fendido no ápice. Esquizocarpo ca. 1,6 mm diâm., depresso-globoso; núculas ca. 1,5 mm diâm., trígonas, seríceas, com cicatriz orbicular na região ventral. Sementes ca. $1 \mathrm{~mm}$, trígonas.

Material examinado: BRASIL. Mato Grosso do Sul: Corumbá,VI/1997, fl. fr., Silva 06 (COR, HST, PEUFR); ib., $19^{\circ} 38^{\prime}$ S, 57 $17^{\circ}$ 'W, X/1987, fl., Pott 3634 (CPAP, PEUFR).

Euploca pallescens é reconhecida facilmente pelos ramos amarelo-esverdeados, lâmina foliar estreitamente trulada a lanceolada, atenuada na base, com margem revoluta e pelo estilete obsoleto. A espécie é ilustrada pela primeira vez neste trabalho.

Distribui-se no Paraguai e Brasil, onde foi registrada pela primeira vez. Ocorre no Mato Grosso do Sul associada à depressão pantaneira. Coletada com flores em junho e outubro e, com frutos em junho.

10. Euploca paradoxa (Mart.) J.I.M.Melo \& Semir, Kew Bull. 64(2): 289. 2009. Preslaea paradoxa Mart., Nov. Gen. Sp. Pl. 2: 76. 1827. Tipo: Brasil, s.l., s.d., Martius s.n. (Isótipo: $\mathrm{K}$, fotografia!).

Fig. 4: A-E

Erva ou subarbusto, prostrado, estolonífero ou raramente cespitoso; xilópodio presente ou não. Ramos cilíndricos, com ritidoma desprendendo-se longitudinalmente, escabrosos, menos frequentemente com tricomas ferrugíneos na região apical. Folhas alternas, pecioladas; pecíolo 1-3 mm; lâmina $0,5-2,2 \times 0,1-0,5 \mathrm{~cm}$, patente, cartácea a subcarnosa, lanceolada a largamente lanceolada, ápice agudo, margem inteira, ciliada, base atenuada, pubérula a vilosa em ambas as faces; venação hifódroma. Flores 0,6-1,2 cm, solitárias, axilares, longamente pediceladas; pedicelo $4-9 \mathrm{~mm}$, viloso; brácteas 3,4-4x1-2 mm, foliáceas, elípticas a lanceoladas, vilosas externamente e internamente; cálice 1,7-3,2 mm, lacínios 1,7-4x0,4-0,6 mm, estreitamente lanceolados, vilosos externamente, com margem ciliada, glabros internamente; corola $0,6-1,2 \mathrm{~cm}$, inteiramente amarela, campanulada, tubo 3,5-6,8 mm, lacínios 2,2-3,8x2-2,2 mm, ondulados, orbiculares, sulcados, alternados por apêndices, estes com ca. 1 $\mathrm{mm}$, involutos, falcados, largamente lanceolados; estames subsésseis, filetes inseridos ca. 1,5-2 $\mathrm{mm}$ da base do tubo; anteras ca. $1 \mathrm{~mm}$, ovadas, cordadas na base; ovário ca. 0,5 $\mathrm{mm}$, depresso-globoso; estilete $0,8-1 \mathrm{~mm}$, cilíndrico; estigma $0,6-0,8 \mathrm{~mm}$, cônico, espessado na base, arredondado no ápice, pubérulo. Esquizocarpo 1,5-1,8 mm diâm., depressopiriforme, com arestas, rostrado; núculas ca. 1,5 mm diâm., com cicatriz crateriforme, pubérulas, tricomas falcados, hialinos, alvos ou ferrugíneos. Sementes $1 \mathrm{~mm}$, elípticas.

Material selecionado examinado: BRASIL. Bahia: Bom Jesus da Lapa, II/1991, fl. fr., Hatschbach \& Ribas 55170

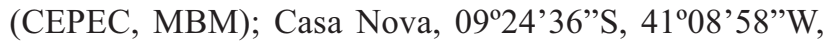
IV/2001, fl., Harley et al. 54333 (CEPEC); Guanambi, I/1997, fl. fr., Hatschbach \& Ribas 65508 (HRCB, MBM); Ibotirama, $12^{\circ} 22^{\prime} \mathrm{S}, 43^{\circ} 13^{\prime} \mathrm{W}$, III/1982, fl. fr., Krapovickas

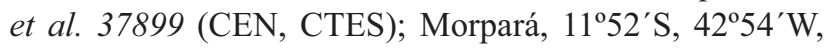
III/1984, fl., Salgado \& Bautista 308 (ALCB, HRB, IPA); Remanso, I/1964, fl., Lima 64-4215 (IPA); Rio de Contas, 1334'09”S, 4149'08”W, XI/1996, fl., PCD 4376 (ALCB, HRB); Santa Maria da Vitória, $13^{\circ} 12^{\prime} \mathrm{S}, 44^{\circ} 04^{\prime} \mathrm{W}, \mathrm{XI} / 1980$, fl., Silva 166 (HRB, CEPEC); Santo Inácio, $11^{\circ} 01^{\prime} \mathrm{S}$, 42 46” W, II/1997, fl. fr., Harley 19111 (IPA, K, UEC); Senhor do Bonfim, V/1974, fl., Lima 74-7627 (IPA). Goiás: Paraúna, XI/1975, fl. fr., Hatschbach 37725 (PEL). Mato Grosso: Santo Antonio do Levérger, 15\%45'11"S, 5604'17'W, X/1978, fl. fr., Duarte \& Assumpção 946 (UEC, UFMT). Paraíba: Areia, VI/1953, fl. fr., Moraes 936 (R). Pernambuco: Ibimirim, V/1982, fl. fr., Lia et al. 46 (IPA); Petrolina, IV/1971, fl., Heringer et al. s/n (PEUFR 5656). Piauí: São Raimundo Nonato, XII/1978, fl. fr., Fernandes et al. $s / n$ (EAC 5181).

Espécie próxima de E. parciflora por compartilharem flores solitárias, longamente pediceladas e, principalmente, pela corola com apêndices alternados aos lacínios. Entretanto, é reconhecida seguramente pelo hábito herbáceo ou subarbustivo, flores axilares, corola alcançando 1,2 cm, inteiramente amarela e, pelos frutos arestados.

Ocorre apenas no Brasil, nas regiões Nordeste (BA, PB, PE, PI) e Centro-Oeste (GO, MT), sendo registrada pela primeira vez nos estados da Paraíba, Pernambuco e no Mato Grosso. Encontrada na Caatinga, raramente em borda de brejo (BA), Cerrado e Cerrado rupestre (PI), em solos arenosos e areno-argilosos, freqüentemente em margens fluviais, principalmente no estado da Bahia, no curso do rio São Francisco. A floração concentra-se entre janeiro e junho, e de outubro a dezembro, a frutificação ocorre entre janeiro e março, maio, junho, novembro e dezembro.

11. Euploca parciflora (Mart.) J.I.M.Melo \& Semir, Kew Bull. 64(2): 289. 2009. Preslaea parciflora Mart., Flora 22(1): 27. 1839. Tipo: Brasil, Cuiabá, s.d., Martius 277 (Isótipo: $\mathrm{K}$ !).

Fig. 4: F-I

Erva, prostrada. Ramos vilosos. Folhas alternas, pecioladas; pecíolo $1 \mathrm{~mm}$, estrigoso; lâmina $0,5-1,2 \times 0,1-0,3$ $\mathrm{cm}$, membranácea, lanceolada a linear-lanceolada, ápice agudo, margem inteira, ciliada, base cuneada, glabra a puberulenta em ambas as faces; venação hifódroma. Flores 6-9 mm, solitárias, supra-axilares, longamente pediceladas; pedicelo 2-4 mm, viloso; cálice 2,2-3,3 mm, lacínios 2,2- 
3,3x0,4-0,8 mm, ovado-lanceolados, vilosos externamente, glabros internamente; corola ca. $9 \mathrm{~mm}$, campanulada, vilosa externamente, glabrescente externamente na região do tubo, tubo 2-2,5 $\mathrm{mm}$, amarelo, lacínios 3,2-4,7 mm, largamente obovados, brancos, alternados por apêndices com ca. $1 \mathrm{~mm}$, falcados, involutos; estames subsésseis, inseridos entre 1,8-2 $\mathrm{mm}$ da base do tubo; anteras $0,8-1$ $\mathrm{mm}$, largamente ovadas; ovário ca. $0,6 \mathrm{~mm}$, subgloboso, glabro; estilete ca. $0,8 \mathrm{~mm}$; estigma ca. $0,4 \mathrm{~mm}$, cônico, disco espessado na base. Esquizocarpo 1-1,5 mm diâm., piriforme, sem arestas; núculas ca. $1 \mathrm{~mm}$, trígonas, vilosas apenas na porção superior. Sementes ca. $1 \mathrm{~mm}$, elípticas.

Material selecionado examinado: BRASIL. Goiás: Teresina de Goiás, XII/1991, fl. fr., Pereira et al. 1938 (IBGE, RB, UEC); ib., $13^{\circ} 30^{\prime} \mathrm{S}, 4^{\circ} 30^{\prime} \mathrm{W}, \mathrm{XI} / 1996$, fl. fr., Pereira \& Alvarenga 3311 (IBGE, RB, UEC, US). Mato Grosso do Sul: Xavantina, $14^{\circ} 38^{\prime}$ S, $52^{\circ} 14^{\prime} \mathrm{W}, \mathrm{XI} / 1968$, fl. fr., Harley \& Souza 11035 (K). Piauí: Floriano, III/2005, fl. fr., Miranda et al. 5033 (HST). Tocantins: Conceição do Tocantins, $12^{\circ} 39^{\prime} \mathrm{S}, 47^{\circ} 06^{\prime} \mathrm{W}, \mathrm{XI} / 1998$, fl. fr., Ratter et al. 8150 (UEC).

Euploca parciflora é morfologicamente semelhante a $E$. lagoensis e E. paradoxa, principalmente no aspecto geral e, também, por compartilharem flores solitárias, longamente pediceladas, supra-axilares. Entretanto, pode ser prontamente reconhecida, principalmente, pela corola com ca. $9 \mathrm{~mm}$, lacínios da corola largamente obovados com apêndices e, ainda, pela presença de estilete.

O espécime typus de E. parciflora foi coletado no Mato Grosso, consistindo, até o momento, na única coleção obtida para o Estado. Distribui-se nas regiões Norte (TO), CentroOeste (GO, MS) e Nordeste (PI). Foi registrada pela primeira vez nas regiões Norte (TO) e Nordeste (PI). Está associada ao cerrado $(\mathrm{GO}, \mathrm{TO})$, inclusive em cerrado rupestre (PI), sendo encontrada em margens de estradas, geralmente em solo cascalhento. Coletada com flores e frutos em março, novembro e dezembro.

\section{Euploca polyphylla (Lehm.) J.I.M.Melo \& Semir, Kew} Bull. 64(2): 289. 2009. Heliotropium polyphyllum Lehm., Neue Schriften Naturf. Ges. Halle 3(2): 9. 1817. Tipo: Venezuela, ad Oronocum, s.d., Humboldt s.n. (Holótipo: Iconografia, W).

Fig. 4: J-N

Erva ou subarbusto, prostrado ou decumbente, com indumento seríceo, esbranquiçado nos ramos, folhas, inflorescências, flores e frutos. Ramos difusos, cilíndricos, revestimento semelhante a ritidoma desprendendo-se em faixas longitudinais. Folhas alternas ou subopostas, pecioladas; pecíolo 0,3-1 mm, achatado, seríceo, nunca decorrente; lâmina $0,6-1,3 \times 0,1-0,2 \mathrm{~cm}$, cartácea a subcoriácea, estreitamente lanceolada ou oblanceolada, ápice agudo, base cuneada, margem plana, esparsa a densamente serícea em ambas as faces; venação hifódroma. Inflorescência 1-15,5 $\mathrm{cm}$, terminal, solitária ou aos pares; brácteas 3-4x1-1,3 $\mathrm{mm}$, ovadas, cartáceas, venação semelhante à das folhas, glabras externamente, seríceas internamente. Flores 6-6,5 $\mathrm{mm}$, pediceladas; pedicelo ca. $0,5 \mathrm{~mm}$; cálice ligeiramente menor que o tubo corolino, profundamente partido, lacínios 3-4 mm, desiguais entre si, os menores $2-2,5 \times 0,6-0,8 \mathrm{~mm}$, os maiores 3-4x0,8-1 mm, foliáceos, ovados a largamente ovados, margem inteira, ciliada, ápice agudo, externamente seríceos, internamente glabros; corola 6-6,5 mm, tubular, amarela ou branca, serícea externamente, tubo 3,6-4 mm, internamente seríceo na fauce, lacínios 2,5-3 mm, ovadodeltóides; estames subsésseis, filetes inseridos $1 \mathrm{~mm}$ da base do tubo; anteras ca. $1 \mathrm{~mm}$, ovadas, base truncada, longamente apiculadas; ovário ca. $0,5 \mathrm{~mm}$, subgloboso, 4-sulcado, glabro; estilete evidente ca. 0,3-0,6 mm, cilíndrico; estigma ca. 0,4 mm, cônico, 4-fendido no ápice, com superfície cerdosa. Esquizocarpo ca. 1,5 mm diâm., subgloboso, totalmente recoberto pelo cálice; núculas ca. 1,5 mm diâm., trígonas, seríceas. Sementes ca. $1 \mathrm{~mm}$, trígonas.

Nomes populares: cachinho-branco (MA); crista-degalo (PI).

Material selecionado examinado: BRASIL. Alagoas: Feliz Deserto, XI/1998, fl. fr., Lemos et al. 4034 (MAC); Maceió, III/1993, fl. fr., Correia s/n (MAC 0039); Piaçabuçu, V/1983, fl. fr., Rocha 521 (MAC). Bahia: Campo Alegre de Lourdes, $09^{\circ} 37^{\prime} 15^{\prime \prime} \mathrm{S}, 42^{\circ} 32^{\prime} 38^{\prime \prime} \mathrm{W}, \mathrm{VI} / 2001$, fl. fr., Nunes et al. 456 (HUEFS); Conde, $11^{\circ} 48^{\prime} \mathrm{S}, 37^{\circ} 36^{\prime} \mathrm{W}$, XII/1999, fl. fr., Guedes et al. 7382 (ALCB, CEPEC); Jacobina, 1837, fl. fr., Blanchet 2651 (SP); Juazeiro, II/1968, fl., Pontual 68-762 (PEUFR); Nova Remanso, VIII/1984, fl., Orlandi et al. 674 (GUA, HRB); Remanso, 09²0'S, $42^{\circ} 00^{\prime} \mathrm{W}, \mathrm{II} / 1972$, fl. fr., Pickersgill et al. 72-112 (IPA); Xique-xique, $10^{\circ} 50$ 'S, 42'42”'W, XI/1984, fl., Noblick 3466 (CEPEC, HUEFS). Ceará: Aquiraz, X/1935, fl. fr., Drouet 2629 (R); Aracati, XI/1999, fl. fr., Jardelina 07 (MOSS); Beberibe, I/1990, fl. fr., Mendonça 1590 (IBGE, UCS, UEC, US); Caucaia, II/1998, fl., Souza s/n (EAC 26378); Estrada Matriz-Serrota, VI/1984, fl. fr., Bohrer \& Orlandi 40 (HRB); Fortaleza, V/1997, fl. fr., Castro \& Filgueiras $s / n$ (EAC, IBGE 41353); Ibiapaba, I/1968, fl., Lima 685201 (IPA); Jijoca de Jericoacoara, II/2000, fl., Matias 262 (EAC). Maranhão: Alcântara, II/1984, fl. fr., Carvalho et al. 2064 (CEPEC); Ilha de São Luiz, IV/1945, fl. fr., Fróes 21594 (IAC). Pará: Maracanã, I/1988, fl., Araújo 8466 (GUA); Salinópolis, XII/1997, fl., Araújo 10615 (GUA). Paraíba: Araruna, VII/2003, fl., Almeida et al. 413 (EAN); Ilha Bela, XII/1997, fl., Costa e Silva et al. 1440 (PEUFR); Lucena, XII/1997, fl., Pereira et al. 1322 (HST, IPA, JPB); São João do Cariri, 07²1'29'S, 36³1'57'W, IV/2002, fl. fr., Barbosa et al. 2333 (JPB). Pernambuco: Ibimirim, VI/1995, fl., Ferraz \& Ferreira s/n (IPA 67562); Petrolina, VI/1983, fl. fr., Fotius 3502 (IPA) Santa Maria da Boa Vista, IV/1988, fl. fr., Pereira 309 (HST, IPA). Piauí: Brasileira,

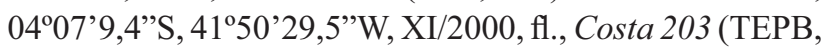

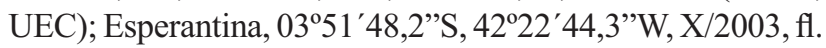
fr., Franco 142 (HST, TEPB); Luís Corrêa, VI/1990, fl. fr., 


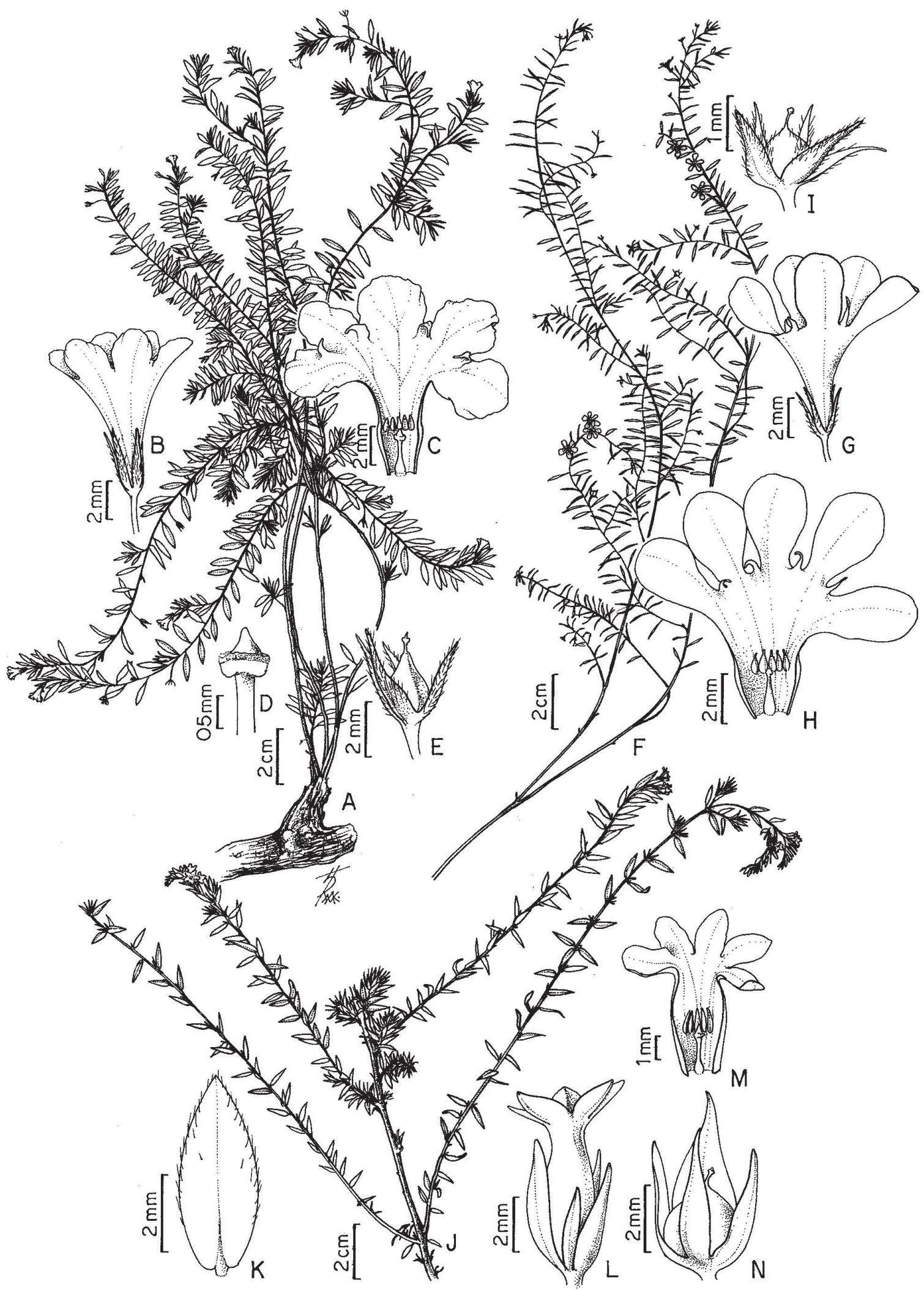

Figura 4. A-N. Euploca paradoxa (Mart.) J.I.M.Melo \& Semir (Krapovickas 37899): A. Ramo reprodutivo. B. Flor. C. Corola rebatida, evidenciando androceu e gineceu. D. Estigma. E. Fruto, em vista lateral. E. parciflora (Mart.) J.I.M. Melo \& Semir (Miranda et al. 5033): F. Ramo reprodutivo. G. Flor. H. Corola rebatida, evidenciando androceu e gineceu. I. Fruto, em vista lateral. E. polyphylla (Lehm.) J.I.M.Melo \& Semir (Melo et al. 513): J. Ramo reprodutivo. K. Bráctea. L. Flor. M. Corola rebatida, evidenciando androceu e gineceu. N. Fruto, evidenciando cálice acrescente (Melo et al. 511 ). 
Montes et al. 05 (HRB); Parnaíba, VII/1954, fl., Lima 541976 (IPA); Pedro II, IV/2006, fl. fr., Barros 2766 (PEUFR, TEPB); São Raimundo Nonato, 0909'S, 42³4'W, IV/1984, fl. fr., Miranda 443 (CEPEC). Rio de Janeiro: Arraial do Cabo, VIII/1987, fl. fr., Araújo 7957 (GUA); Cabo Frio, V/1986, fl. fr., Araújo 7431 (GUA); Campos, III/1939, fl. fr., Sampaio 8170 (R). Rio Grande do Norte: Caraú, IV/2005, fl. fr., Melo et al. 513 (PEUFR); Caraubas, XI/1980, fl. fr., Agra 220 (JPB); Extremoz, VIII/1993, fl. fr., Amaral 05 (MOSS); João Câmara, 05³2'15”S, 3549'11”W, VI/1999, fl. fr., Lopes 01 (MOSS); Mossoró, IV/2005, fl. fr., Melo et al. 512 (PEUFR); Parnamirim, VII/1980, fl. fr., Coradin et al. 3204 (CEN); Tibau, 0450'00"S, 37¹5'00”W, XI/1997, fl.

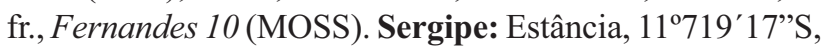
37¹7’32”W, VI/1994, fl., fr. , Mattos Silva et al. 3031 (CEPEC); Pirambu, I/1974, fl. fr., Fonseca s/n (ASE 00005).

Material adicional examinado: VENEZUELA. Guárico: Llanos de la Ribera, IV/1927, Pittier 12335 (VEN); Parmana, IX/1955, fl., Tamayo 4155 (VEN). Miranda: Rio Chico, I/1957, fl., Aristeguieta \& Medina 2689 (VEN).

Euploca polyphylla é morfologicamente semelhante à E. potti por apresentarem, principalmente, inflorescências laxas com brácteas foliáceas. É reconhecida facilmente pelo hábito, prostrado ou decumbente, com ramos difusos, lâmina foliar estreitamente lanceolada ou oblanceolada com base cuneada, corola geralmente amarela ou menos freqüentemente branca, com lacínios ovado-deltóides e pelo estilete evidente, levemente 4-fendido no ápice.

Ocorre na Venezuela e, no Brasil, nas regiões Norte (PA), Nordeste (AL, BA, CE, MA, PB, PE, PI, RN, SE) e Sudeste (RJ). É encontrada desde ambientes litorâneos (restingas) até a caatinga hiper-xerofítica, nos estados da Bahia, Ceará, Paraíba, Pernambuco, Piauí e Rio Grande do Norte ou, mais raramente, em cerrado (PI) e no ecótono caatinga-floresta estacional (CE), associada a solos arenosos ou areno-argilosos, em elevações até $750 \mathrm{~m}$. O estado do Rio de Janeiro é o limite meridional de distribuição da espécie. Floresce e frutifica praticamente o ano inteiro, com exceção de setembro.

13. Euploca pottii J.I.M.Melo \& Semir, Kew Bull. 64(2): 286. 2009. Tipo: Brasil, Mato Grosso do Sul, Corumbá, IX/1994, Pott et al. 1397 (Holótipo: CPAP!; Isótipo: CTES!, UEC!).

Fig. 5: A-F

Erva, prostrada. Ramos cilíndricos ou angulosos somente na região mediana superior, escabrosos, com tricomas esbranquiçados, na maioria adpressos. Folhas alternas, pecioladas; pecíolo 1-4 mm, sulcado, estrigiloso, nunca decorrente; lâmina 0,7-2,3x0,2-0,6 cm, subcartácea, elíptica, ápice agudo, base cuneada, margem inteira, não revoluta, ciliada, estrigosa em ambas as faces; venação hifódroma, com nervura proeminente na face adaxial. Inflorescência 6,6 $\mathrm{cm}$, terminal, laxa, multiflora; pedúnculo $1 \mathrm{~cm}$, estrigoso; brácteas $0,7-1 \times 0,25-0,4 \mathrm{~cm}$, foliáceas, largamente elípticas, ápice agudo, pubérulas em ambas as faces, subsésseis. Flores 4-7,8 mm, subsésseis; cálice 2,8-4,3×0,6-0,8 mm, lacínios desiguais entre si, o maior $4,2 \times 0,8 \mathrm{~mm}$, os intermediários $4 \times 0,6 \mathrm{~mm}$, os menores $2,7 \times 0,6 \mathrm{~mm}$, elípticos, externamente estrigosos, apenas os tricomas localizados na base castanhos, alternados por pontuações enegrecidas; corola 4-7,5 mm, tubular, branca, tubo 3-5 mm, seríceo externamente, anel viloso situado internamente à altura da constricção, lacínios 1-2x0,5-0,8 mm, elípticos; estames subsésseis, filetes inseridos ca. $0,5 \mathrm{~mm}$ da base do tubo; anteras ca. $1 \mathrm{~mm}$, ovadas, cordadas na base, longamente apiculadas; ovário ca. $0,5 \mathrm{~mm}$, subgloboso; estigma ca. $0,5 \mathrm{~mm}$, estilete ausente, ápice 4-corniculado, base delgada, porção mediana inferior escura, porção mediana superior esbranquiçada, superfície cerdosa. Esquizocarpo não observado.

Material examinado: BRASIL. Mato Grosso do Sul: Corumbá, IX/1994, fl., Pott et al. 1397 (CPAP, CTES, UEC).

Euploca pottii é morfologicamente semelhante a $E$. polyphylla, em relação às suas inflorescências multifloras, de flores de disposição laxa e pelas brácteas foliáceas. No entanto, E. pottii difere desta última por apresentar brácteas com ca. $1 \mathrm{~cm}$, largamente elípticas, corola 4-7,5 mm com lacínios ca. $2 \mathrm{~mm}$, elípticos, base das anteras cordadas e, especialmente, pelo estigma séssil. Além disso, ambas as espécies apresentam-se com distribuição geográfica distinta. E. pottii apresenta uma distribuição restrita sendo encontrada, até o momento, no Mato Grosso do Sul, enquanto que E. polyphylla, no Brasil, ocorre nas porções norte e leste, desde o Pará até o Rio de Janeiro.

14. Euploca procumbens (Mill.) Diane \& Hilger, Bot. Jahrb. Syst. 125(1): 48. 2003. Heliotropium procumbens Mill., Gard. Dict. 8: 10. 1768. Tipo: Colômbia, Bolivar, Cartagena, s.d., Houston s.n. (Síntipo: BM).

Fig. 5: G-K

Erva ou subarbusto, $5-50 \mathrm{~cm}$, ereto ou prostrado, indumento seríceo, nos ramos, folhas e flores. Ramos cilíndricos, verde-cinéreos. Folhas alternas, pecioladas; pecíolo 0,4-2,4 $\mathrm{cm}$, subcilíndrico, ventralmente sulcado; lâmina 1-7,5x0,3$2,4 \mathrm{~cm}$, subcarnosa, estreitamente elíptica, elíptica a oblongo-elíptica, ápice agudo, mucronado, base atenuada, margem inteira, serícea em ambas as faces; venação broquidódroma, face adaxial com nervuras secundárias pouco evidentes, face abaxial com nervura proeminente. Inflorescência 1-9 cm, terminal e axilar, inteira ou bifurcada, 1-4 partindo de um mesmo ponto, seríceas, abracteadas; pedúnculo $0,9-3 \mathrm{~cm}$, seríceo ou estrigoso. Flores 1,6-2 mm, subsésseis; cálice profundamente lobado, ligeiramente menor que o tubo da corola, lacínios 1-1,3 mm, ovados a ovado-lanceolados; corola 1,5-2 mm, tubular, branca, fauce amarela, tubo 1-1,4 mm, cilíndrico, lacínios ca. $0,3 \mathrm{~mm}$, obovados, patentes; estames subsésseis, filetes inseridos ca. $1 / 3$ da base do tubo, anteras 0,5-0,7 mm, ovadas a ovado-lanceoladas, ápice caudado; ovário ca. 0,3 mm, subgloboso, seríceo; estilete obsoleto, 
recoberto pelo estigma; estigma ca. $0,3 \mathrm{~mm}$, cônico, pubescente, disco estigmático ca. $0,4 \mathrm{~mm}$. Esquizocarpo ca. 1 mm diâm., subgloboso; núculas ca. 1 mm diâm., trígonas, seríceas a hirsutas. Sementes $1 \mathrm{~mm}$, trígonas.

Nome popular: crista-de-galo (BA).

Material selecionado examinado: BRASIL. Acre: Rio Branco-Brasiléia, X/1980, fl. fr., Nelson 753 (INPA). Alagoas: Arapiraca, V/1982, fl. fr., Lyra-Lemos \& Staviski 478 (MAC); Estrela de Alagoas, 09 23'00"S, 3646'15”'W, s/d, fl. fr., Lyra Lemos 5343 (IMA); Piranhas, X/1999, fl. fr., Silva \& Moura 1128 (PEUFR); Traipu, V/1990, fl. fr., Lyra-Lemos \& Esteves 2534 (MAC). Bahia: Abaíra, $13^{\circ} 18^{\prime}$ 'S, $41^{\circ} 48^{\prime} \mathrm{W}, \mathrm{XII} / 1992$, fl. fr., Hind et al. 50477 (CEPEC, HUEFS, K, SPF); Caraíba, VIII/1994, fl. fr., Guedes $s / n$ (ALCB 26953, CTES 284223); Glória, VII/1995, fl. fr., Bandeira 250 (HRB, IPA, HUEFS); Irecê, V/1984, fl. fr., Fotius 3859 (IPA); Itiúba, $10^{\circ} 42^{\prime}$ 'S, 3950'W, I/1997, fl. fr., Arbo et al. 7298 (CEPEC, CTES); Jacobina, X/1995, fl. fr., Jardim et al. 695 (CEPEC); Jequié, III/1977, fl. fr., Sheperd et al. 4458 (UEC); Juazeiro, III/2004, fl. fr., Félix et al. 10117 (EAN); Lagoa da Eugenia, 10 $40^{\circ} \mathrm{S}, 39^{\circ} 43^{\prime} \mathrm{W}, \mathrm{II} / 1974$, fl. fr., Harley 16238 (IPA, K); Livramento de Nossa Senhora,

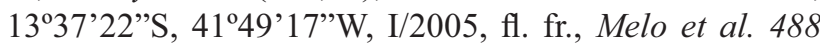
(PEUFR); Queimadas, 1055'35”'S, 39³6’00”'W, XI/1986, fl. fr., Queiroz 1157 (HUEFS); Rio de Contas, I/2005, fl. fr., Melo et al. 489 (PEUFR); São Sebastião do Passé, X/1998, fl. fr., Nascimento et al. 91 (ALCB); Tucano, X/1961, fl. fr., Lima 61-3941 (IPA). Ceará: Caridade, II/1997, fl. fr., Ferrucci \& Figueiredo 1138 (CEPEC); Crato, VIII/1986, fl. fr., Lima 270 (IPA); Santana do Cariri, XII/1981, fl. fr., Peixoto \& Peixoto 1645 (UEC); Serra de Baturité, X/1939, fr., Eugenio 80/A (RB); Quixadá, IV/2005, fl. fr., Melo et al. 501 (PEUFR). Goiás: Campinaçu, X/1995, fl. fr., Walter 2782 (CEN); Niquelândia, VII/1994, fl. fr., Filgueiras \& Oliveira 2969 (IBGE, UEC). Maranhão: Benedito Leite, I/2005, fl. fr., Miranda et al. 4770 (HST); Santa Inês, X/1975, fl. fr., Santos 3069 (CEPEC). Mato Grosso: Poconé, IX/1991, fl. fr., Schessl 2207 (CH); Xavantina, VII/1976, fl. fr., Ratter \& Fonseca-Filho 3292 (UEC). Mato Grosso do Sul: Corumbá, VII/1992, fl. fr., Rocha et al. 15 (COR, UFMS); Entre Rios, VII/1980, fl. fr., Coradin et al. 3035 (CEN); Ladário, XI/1982, fl. fr., Paula \& Conceição 1631 (IBGE); Transpantaneira, I/1979, fl. fr., Heringer et al. 876 (IBGE, UEC). Minas Gerais: Belo Horizonte, s/d, fl. fr., Ferrari 754 (HBCB); Dourados, I/1997, fl. fr., Hatschbach et al. 65782 (MBM); Monte Azul, III/1995, fl. fr., Hatschbach \& Silva 61886 (MBM); Neves, s/d, fl. fr., Madalena \& TSMG 455 (BHCB); Santa Luzia, I/1935, fl. fr., Barreto 2133 (MHN); São Romão, VII/1990, fl. fr., Tameirão-Neto 512 (BHCB); Viçosa, s/d, fl. fr., Kuhlmann s/n (VIC 2562); s/município, XI/1968, fl. fr., Duarte 11274 (BHMH, RFA). Pará: Conceição do Araguaia, IX/2001, fl. fr., Lobato et al. 2786 (MG); Marabá, VIII/1984, bot. fl. fr., Rosa et al. 4623 (MG); Tucurui, XI/1982, fl. fr., Daly et al. 1261 (MG). Paraíba: Areia, VII/1954, fl. fr., Moraes 1172 (IAN); Ita- poranga, III/1993, fl. fr., Agra et al. 1700 (IPA, NYBG); Patos, IV/2004, fl. fr., Melo \& Xavier 443 (PEUFR); São João do Cariri, XII/1977, fr., Pontual 77-1367 (PEUFR); Solânea, II/2001, fl. fr., Grisi 146 (JPB); Soledade, IV/2004, fl. fr., Melo \& Xavier 433 (PEUFR); Sousa, IV/2005, fl. fr., Melo et al. 492 (PEUFR). Pernambuco: Águas Belas, XI/2004, fl. fr., Melo \& Silva 470 (PEUFR); Exu, XI/1986, fl. fr., Lima 427 (IPA); Garanhuns, XI/2004, fl. fr., Melo \& Silva 481 (PEUFR); Pedra, VI/2005, fl. fr., Melo \& Silva 519 (PEUFR); Pesqueira, II/1962, fl. fr., Fromm et al. 1455 (PEL); Petrolândia, 0905'17'S, 38¹3'42”W, III/2004, Silva 479 (PEUFR); Recife, IX/1997, fl. fr., Gomes et al. 465 (PEUFR, UEC); Saloá, XI/2004, fl. fr., Melo \& Silva 467 (PEUFR); Serra Talhada, VI/2006, fl. fr., Melo et al. 565 (PEUFR); Sertânia, VI/2005, fl. fr., Melo \& Silva 543 (PEUFR). Piauí: São Raimundo Nonato, II/1979, fl. fr., Freire \& Del'Arco $s / n$ (TEPB 336). Rio Grande do Norte: Almino Afonso, 06¹2'30"S, 3745'40”'W, VII/1993, fl. fr., Sobrinho 75 (MOSS); Angicos, 0549'00”'S, 36²8'30”'W, II/1980, fl. fr., Oliveira et al. 66 (MOSS); Cruzeta, $06^{\circ} 25^{\prime} \mathrm{S}, 36^{\circ} 47^{\prime} \mathrm{W}$, XI/1986, fl. fr., Cestaro 28 (IPA); Florânia, IV/2004, fl. fr., Melo \& Xavier 447 (PEUFR); Major Sales, IV/2005, fl. fr., Melo et al. 493 (PEUFR); Tenente Laurentino da Cruz, IV/2004, fl. fr., Melo \& Xavier 449 (PEUFR). Rio Grande do Sul: Camaquã, V/1989, fl. fr., Jarenkow \& Waechter 1313 (FLOR, PEL); Porto Alegre, IV/1949, fl. fr., Rambo 41179 (HBR); São Gabriel, I/1944, fl. fr., Rambo 25863 (HBR); São Leopoldo, I/1951, fr., Sehnem 7816 (PEL). Rondônia: Abunã, VII/1998, fl. fr., Prance et al. 6199 (R). Roraima: Boa Vista, II/1964, fl. fr., Silva et al. 07 (MG). Santa Catarina: Itapiranga, III/1964, fl. fr., Klein 5199 (HBR); Mondaí, I/1957, fl. fr., Smith \& Reitz 9741 (HBR). São Paulo: Campinas, I/1990, fl. fr., Bernacci 25919 (UEC); Piracicaba, V/1994, fl. fr., Barreto et al. 2509 (SJRP); Porto Epitácio, VII/1969, fl. fr., Hatschbach \& Guimarães 21740 (HBR, MBM, RFA, UEC); São Carlos, XII/1961, fl. fr., Eiten \& Campos 3475 (SP). Sergipe: Canindé do São Francisco, IV/1999, fl. fr., Moura \& Silva 116 (PEUFR).

Material adicional examinado: ARGENTINA. Corrientes: Dept ${ }^{\circ}$ Capital, XI/1971, fl. fr., Krapovickas \& Cristóbal s/ $n$ (IAC 22599). BOLÍVIA. Dept ${ }^{0} \mathbf{S t}^{\mathbf{a}}$ Cruz: Prov. Andrés Ibañez, I/1987, fl. fr., Nee 33666 (PEL). Pando: Abuña, VII/1968, fl., Prance et al. 6119 (R).VENEZUELA. Amazonas: Isla Raton, IV/1978, fl. fr., Morillo 7373 (MO, VEN). Apure: El Yagual, V/1940, fl. fr., Chardon 43 (VEN). Aragua: Maracay, XI/1982, fl. fr., Guevara \& Carmona 3134 (MY, VEN). Bolivar: Ciudad Bolivar, VI/1961, fl. fr., Aristeguieta 4691 (VEN). Miranda: Cojedes, IV/1994, fl. fr., Delascio \& Gamarra 16028 (VEN). Rio Chico, VI/1923, fl. fr., Jahn 1255 (VEN). Portuguesa: XII/1925, fl. fr., Pittier 12035 (VEN); Guanare, 0850'N, 69¹8'W, III/1982, fl. fr., Liesner \& González 12714 (VEN). Sucre: San Juan, IV/1983, fl. fr., Cumana 1597 (VEN). Zulia: Distrito Bolívar, V/1979, fl. fr., Bunting \& Galué 7592 (VEN). 
Euploca procumbens é morfologicamente semelhante às espécies E. barbata e E. filiformis, com as quais compartilha o aspecto geral e, principalmente, apenas com E. barbata por apresentarem os ramos verde-cinéreos e inflorescências sem brácteas. É reconhecida facilmente pelos ramos verdecinéreos, tubo da corola de comprimento igual ou ligeiramente menor que o cálice, lacínios da corola obovados e pelo estigma pubescente. Além disso, esta última espécie restringe-se à Caatinga, enquanto que E. procumbens ocorre em todo o Brasil.

Estende-se do sul dos Estados Unidos até Argentina, inclusive nas Antilhas e, no Brasil, nas regiões Norte (AC, PA, RO, RR), Nordeste (AL, BA, CE, MA, PB, PE, PI, RN, $\mathrm{SE}$ ), Centro-Oeste (GO, MT, MS), Sudeste (MG, SP) e Sul $(\mathrm{RS}, \mathrm{SC})$. É referida pela primeira vez para o estado de Roraíma. Encontrada em todas as formações vegetacionais, principalmente na caatinga, onde é freqüentemente observada sincronopatricamente com Heliotropium angiospermum Murray e H. elongatum (Lehm.) I.M. Johnst. Geralmente está associada a ambientes palustres, como: orlas de rios, riachos, açudes, charcos, regatos e em orlas de matas ciliares, especialmente no complexo pantaneiro e Cerrados, formando densas populações. Coletada com flores e frutos todo o ano.

\section{Euploca rodaliae J.I.M.Melo \& Semir, Candollea 61(2):} 454. 2006. Tipo: Brasil, Bahia, Estrada Rio-Bahia, III/1958, Andrade-Lima 58-2919 (Holótipo: PEUFR!; Isótipo: IPA!).

Fig. 5: L-Q

Subarbusto, 0,3-1,1 m, ereto. Ramos cilíndricos, flexíveis, escabrosos, seríceos. Folhas alternas ou menos freqüentemente opostas somente na região dos internós, pecioladas; pecíolo decorrente; lâmina 1,3-3,3x0,5-1 cm, membranácea a subcarnosa, discolor, ovada, ovado-lanceolada ou, menos freqüentemente, espatulada a obovada, ápice mucronado a agudo, base truncada, margem levemente revoluta a sinuada, ciliada, puberulenta ou estrigosa na face adaxial, densamente estrigosa a setácea na face abaxial, esbranquiçada, tricomas de base inflada em ambas as faces; venação broquidódroma, com nervuras impressas na face adaxial, proeminentes na face abaxial. Inflorescência 1,9-8,4 cm, terminal e axilar, dicótoma, laxa, discretamente escorpióide; pedúnculo 0,7-1,4 cm; brácteas 4,5x1,5 mm, lanceoladas, estrigosas. Flores 5,5-7 mm, subsésseis; cálice 4,5-5,5 mm, lacínios 4-6 x 0,4-1 mm, subcarnosos, alados, lineares a lanceolados, externamente setáceos, internamente glabros, margem ciliada, esbranquiçada, com pontuações enegrecidas esparsas, porção central esverdeada; corola 5-6,6 mm, tubular, branca, serícea externamente, vilosa internamente apenas na área de inserção dos estames, tubo 3,5-4 mm, lacínios ca. $2 \times 2 \mathrm{~mm}$, patentes, largamente deltóides, ondulado-plicados; estames subsésseis, filetes inseridos ca. $1,5 \mathrm{~mm}$ da base do tubo; anteras $1 \mathrm{~mm}$, conatas, ovadas a ovado-lanceoladas; ovário 0,5-0,7 mm, depresso-globoso, sulcado, estipitado; estilete ca. $1 \mathrm{~mm}$, cilíndrico; estigma $0,5-0,7 \mathrm{~mm}$, porção fértil largamente cônica, levemente fendida no ápice, pubérulo. Esquizocarpo 2-2,5 mm diâm., depresso-globoso; núculas 1,5-2 mm diâm., trígonas, pubescentes. Sementes 1-1,2 mm, elípticas.

Material examinado: BRASIL. Bahia: Barreiras, IX/1978, fl. fr., Coradin et al. 1177 (CEN); Caetité, $13^{\circ} 59^{\prime} 35^{\prime}$ 'S, 42 $12^{\circ} 27^{\prime \prime} W$, II/1997, fl. fr., Saar et al. 5242 (ALCB, CEPEC, HRB, HUEFS); ib., 1351'17'S, $42^{\circ} 16^{\prime} 12^{\prime}$ 'W, II/1997, fl. fr., PCD 5199 (ALCB, CEPEC, HUEFS); Estrada Rio-Bahia, III/1958, fl. fr., Lima 58-2919 (IPA, PEUFR); Santaluz, 11¹1'16”'S, 39²5'48”'W, XI/1986, fl., Queiroz et al. 1127 (HUEFS). Pernambuco: Caruaru, 1998, fl. fr., V.C. Lima s.n. (IPA 65497); Gravatá, VIII/1996, fl. fr., Miranda et al. 2399 (HST).

Euploca rodaliae é morfologicamente semelhante a $E$. hassleriana, com a qual compartilha, principalmente, pecíolo decorrente e as inflorescências com brácteas. Caracteriza-se pelo hábito exclusivamente subarbustivo, folhas discolores ovadas, ovado-lanceoladas, espatuladas a obovadas, nervuras impressas na face adaxial, proeminentes na face abaxial, base da lâmina foliar truncada, inflorescência terminal, axilar, dicótoma e, principalmente, pelo cálice com lacínios subcarnosos, alados e pelo ovário estipitado.

Restringe-se, até o momento, ao Nordeste do Brasil, nos estados de Pernambuco e Bahia. Em Pernambuco, está associada à Caatinga e, na Bahia, em Caatinga e Cerrado nas porções noroeste e sudoeste do Estado. Na vegetação de Cerrado, cresce em latossolos arenosos com afloramentos areníticos. Ocorre isoladamente ou formando pequenos agrupamentos, geralmente em margens de estradas em cotas altitudinais que variam de 560 a $940 \mathrm{~m}$. Floresce em fevereiro, março, agosto, setembro e novembro, e frutifica em fevereiro, março, agosto e setembro (Melo \& Semir 2006).

16. Euploca salicoides (Cham.) J.I.M.Melo \& Semir, Kew Bull. 64(2): 289. 2009. Heliotropium salicoides Cham., Linnaea 8: 117. 1833. Tipo: Brasil, s.1., s.d., Sellow 5436 (Isótipo: GH!; K!).

Fig. 6: A-G

Subarbusto ou arbusto, $20-90 \mathrm{~cm}$, ereto, prostrado, ou raramente um arbusto escandente, glauco ou cinéreo; xilopódio presente ou não. Ramos estriados, estrigosos a vilosos, tricomas hialinos, ferrugíneos ou não. Folhas alternas, espiraladas; pecioladas ou subsésseis; pecíolo 2 $\mathrm{mm}$, viloso, nunca decorrente; lâmina $0,7-5 \times 0,15-1,4 \mathrm{~cm}$, ascendente, membranácea a subcartácea, discolor, lanceolada, oblongo-lanceolada, ovado-lanceolada a largamente ovada, ápice agudo, base truncada a arredondada, margem pouco a fortemente revoluta, ciliada, face adaxial hirsuta a vilosa, com nervura central impressa, face abaxial estrigosa a tomentosa, nervura central proeminente, às vezes entremeadas com tricomas uncinados, hialinos; venação hifódroma. Inflorescência 1,1-15 cm, terminal, solitária ou 2-3 agrupada, congesta; pedúnculo $0,2-2,7 \mathrm{~cm}$, estrigoso a 


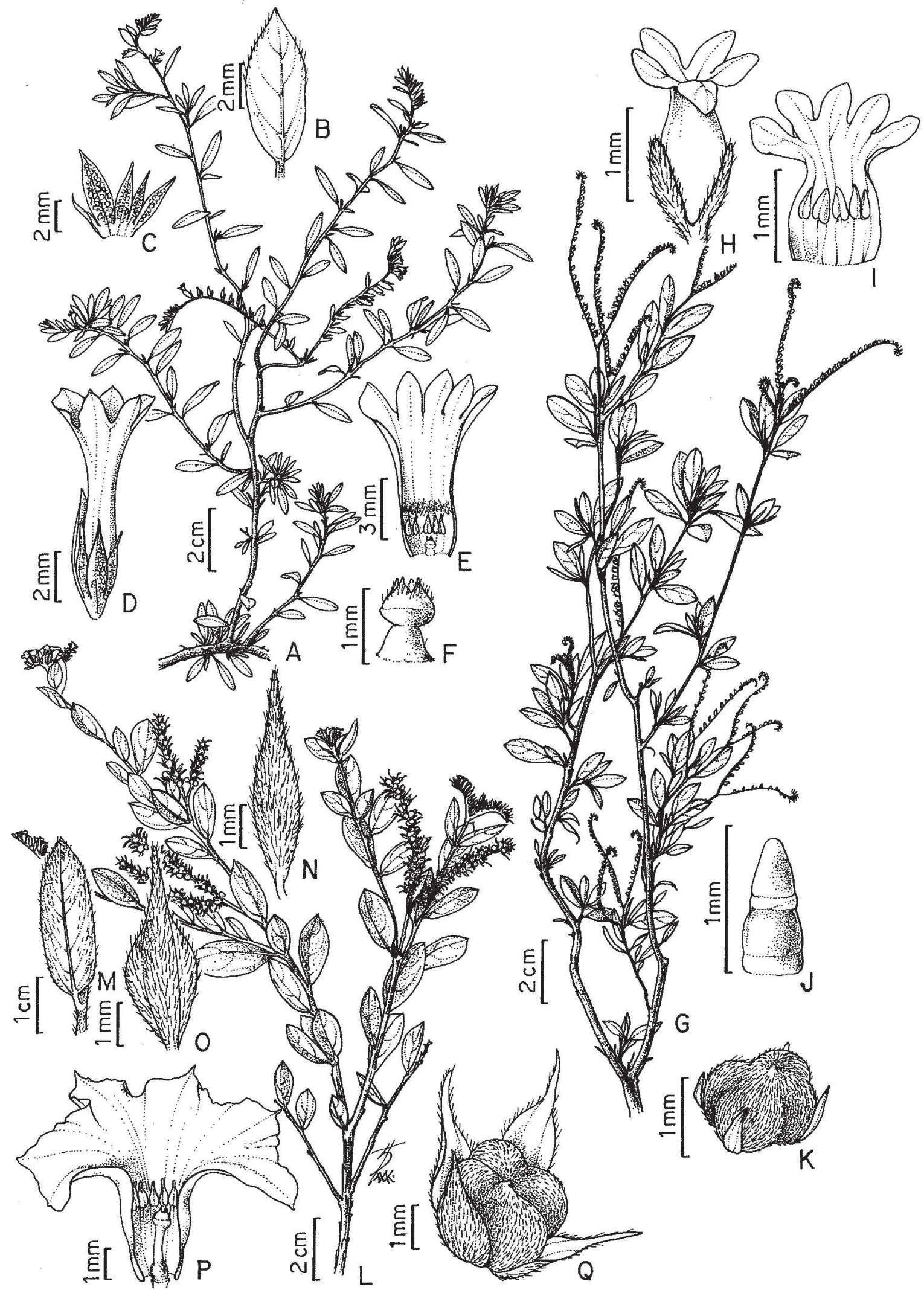

Figura 5. A-Q. Euploca pottii J.I.M.Melo \& Semir (Pott 1397): A. Ramo reprodutivo. B. Bráctea. C. Cálice. D. Flor. E. Corola rebatida, evidenciando androceu e gineceu. F. Gineceu. E. procumbens (Mill.) Diane \& Hilger (Melo et al. 493): G. Ramo reprodutivo. H. Flor. I. Corola rebatida, evidenciando androceu e gineceu. J. Gineceu. K. Fruto, em vista frontal. E. rodaliae J.I.M.Melo \& Semir (Coradin et al. 1177): L. Ramo reprodutivo. M. Folha. N. Bráctea. O. Lacínio do cálice. P. Corola rebatida, evidenciando androceu e gineceu. Q. Fruto, em vista frontal. 
tomentoso; brácteas 2-5x0,5-3 mm, foliáceas, ascendentes, membranáceas a subcartáceas, lanceoladas a estreitamente lanceoladas, ovadas a largamente ovadas, pouco a muito revolutas, hirsutas externamente, com tricomas aciculares ou uncinados, glabrescentes internamente. Flores 4-5 mm, pediceladas ou sésseis; pedicelo ca. $1 \mathrm{~mm}$; cálice $2-3 \mathrm{~mm}$, lacínios 2,7-3×1-1,7 mm, elípticos a largamente elípticos, vilosos externamente, glabros internamente; corola 3-5 $\mathrm{mm}$, tubular, amarela ou branca, estrigosa externamente, pubescente internamente apenas na região dos lacínios, tubo 2-2,2 mm, lacínios 3-3,3×1,7-2 mm, suborbiculares, ápice mucronulado; estames subsésseis, filetes inseridos ca. $2 \mathrm{~mm}$ da base do tubo; anteras ca. $1 \mathrm{~mm}$, ovadas, cordadas na base; ovário ca. $0,5 \mathrm{~mm}$, subgloboso, disco nectarífero discreto; estilete evidente ca. $1 \mathrm{~mm}$, cilíndrico; estigma ca. $1 \mathrm{~mm}$, cônico, espessado na base, fendido no ápice. Esquizocarpo ca. $2 \mathrm{~mm}$ diâm., globoso, sulcado, inteiramente recoberto pelo cálice; núculas 1-1,7 mm, trígonas, estrigosas ou pubérulas. Sementes ca. $1 \mathrm{~mm}$, elipsóides.

Nome popular: crista-de-galo (GO).

Material selecionado examinado: BRASIL. Bahia: Aba-

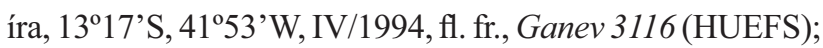
Barra de Estiva, $13^{\circ} 35^{\prime} \mathrm{S}, 41^{\circ} 27^{\prime} \mathrm{W}$, III/1980, fl. fr., Harley et al. 20790 (CEPEC, K); Boqueirão das Lages, V/1975, fl. fr., Barroso et al. s/n (ALCB 3510); Brumado, XII/1989, fl., Carvalho et al. 2619 (CEPEC, HRB, UB); Campo Formoso, $10^{\circ} 22^{\prime} \mathrm{S}, 04^{\circ} 11,9^{\prime} \mathrm{W}, \mathrm{VI} / 1983$, fl., Coradin et al. 6107 (CEN); Caravelas, XI/2005, fl. fr., Miranda 5200 (HST); Cocos,

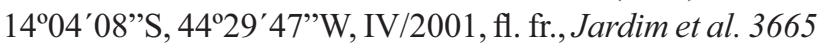
(CEPEC); Correntina, 1307'13”S, 44³9'W, IV/1980, fl., Harley 21905 (CEPEC, K, UEC); Formosa do Rio Preto, $11^{\circ} 06^{\prime} 22^{\prime}$ S, 4524'11'W, XI/1997, fl., Mendonça et al.

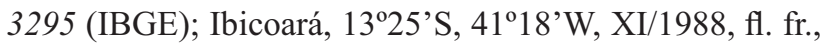
Harley et al. 26968 (CEPEC, K, SPF); Jacobina, $11^{\circ} 05^{\prime}$ S, 40²0'W, I/1997, fl. fr., Arbo et al. 7420 (CEPEC, CTES); Lagoinha, 10²0'S, 4120'W, III/1974, fl. fr., Harley 16846 (CEPEC, IPA, K); Morro do Chapéu, VI/1981, fl., Mori \& Boom 14479 (CEPEC); Mucugê, 1258'30"S, 4128'17'W, II/1992, fl. fr., Queiroz 2655 (HUEFS, PEUFR); Palmeiras, $12^{\circ} 26^{\prime} 70^{\prime \prime}$ 'S, $41^{\circ} 28^{\prime} 27^{\prime \prime} \mathrm{W}, \mathrm{VI} / 1995$, fl. fr., PCD 1964 (ALCB, HUEFS); Rio de Contas, $13^{\circ} 32^{\prime}$ S, $41^{\circ} 50^{\prime} \mathrm{W}, \mathrm{XI} / 1988$, fl. fr., Harley et al. 26006 (CEPEC, HUEFS); Teixeira de Freitas, VIII/1972, fl. fr., Santos 2338 (CEPEC); Tucano, III/1992, fl. fr., Carvalho et al. 3900 (CEPEC). Ceará: Inhuçu, VII/1971, fl. fr., Fernandes s/n (EAC 2293); Ibiapaba, I/1968, fl., Lima 68-5206 (IPA). Distrito Federal: Brasília, $15^{\circ} 45^{\prime}$ 'S, $45^{\circ} 53^{\prime}$ W, II/1986, fl. fr., Nascimento \& Catharina

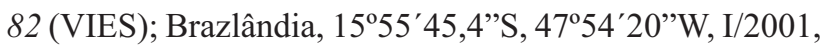
fl. fr., Munhoz et al. 2471 (IBGE, UCS); Rodovia BrasíliaAnápolis, XII/1965, fl. fr., Belém 2020 (CEPEC, UB). Goiás: Alto Paraíso, XI/1987, fl. fr., Castro \& Barbosa 203 (HST, HUFU); Catalão, 18¹0'S, 757'W, I/1996, fl., Pietrobom-Silva 2579 (CTES); Cocalzinho, 15\%44'47'S, 484' '13"W, III/2002, fl. fr., Silva et al. 5125 (IBGE, SJRP, VEN); Niquelândia, 1405'33”S, 48²2'15”'W, XI/1997, fl. fr., Azevedo et al. 1152 (IBGE, UCS, VEN); Pirenópolis, XII/1987, fl. fr., Semir et al. 20649 (UEC); Planaltina,

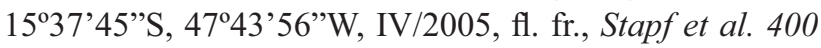
(HUEFS, PEUFR); Pouso Alto, XII/1968, fl., Chaves $s / n$ (PEUFR 34926, JPB 2425); Simolândia, 14²3'45,6”S, 463'22,5W, II/2003, fl. fr., Fonseca et al. 4113 (IBGE, VEN). Mato Grosso: Cuiabá, V/1996, fl. fr., Conceição et al. s/n (CH 13235); Santo Antonio de Leverger, XI/1982, fl. fr., Guarim-Neto 725 (MAC, UFMT). Mato Grosso do Sul: Dourados, X/2003, fl. fr., Hatschbach 76619 (MBM); Rio Brilhante, II/1970, fl. fr., Hatschbach 23681 (HBR, MBM, RFA). Minas Gerais: Botumirim, I/2002, fl., Rodrigues et al. 1364 (UEC); Congonhas do Norte, $18^{\circ} 41^{\prime} \mathrm{S}, 43^{\circ} 42^{\prime} \mathrm{W}$, II/1991, fl. fr., Arbo et al. 5018 (CTES, SPF); DiamantinaCurvelo, XI/1981, fl. fr., Menezes et al. (CFCR) 2597 (SP, UEC); Formoso, 1524'10"S, 4555'33"W, XII/1997, fl., Mendonça et al. 3358 (IBGE, RB, VEN); Gouveia, $18^{\circ} 26^{\prime}$ 'S, 434’'W, II/1991, fl. fr., Arbo et al. 5236 (CTES, SPF); Grão Mogol, 16³3'36,4”S, 4253'45,5”W, I/2002, fl., Flores et al. 792 (UEC); Itaobim, III/1959, fl. fr., Magalhães 15419 (BHCB, BHMB); Pirapora, I/1989, fl. fr., Krapovickas \& Cristóbal 42882 (CTES); São Sebastião do Paraíso, $20^{\circ} 55^{\prime} 54,1^{\prime \prime} \mathrm{S}, 46^{\circ} 55^{\prime} 82,1$ ' $\mathrm{W}, \mathrm{V} / 2003$, fl. fr., Tozzi et al. 2003-72 (UEC); Unaí, 1555'S, 46²40'W, XI/1993, fl. fr., Silva et al. 1741 (IBGE). Paraná: Ponta Grossa, XII/1952, fl., Hatschbach 2895 (ESA, MBM); Vila Velha, I/1987, fl. fr., Krapovickas \& Cristóbal 40887 (CTES). Pernambuco: Buíque,VI/1994, fl., Miranda et al. 1827 (PEUFR). Rio Grande do Sul: Alegrete, II/1990, fl. fr., Falkenberg \& Sobral 5172 (FLOR); Quaraí, I/1945, fl. fr., Rambo 26137 (HBR); Tupanciretã, XII/1986, fl. fr., Sobral et al. 5308 (FLOR, ICN, MBM, UEC). São Paulo: Alto Porã, XI/1994, fl., Marcondes-Ferreira et al. 1070 (SP, SJRP); Buritizal, $20^{\circ} 12^{\prime} 31,2^{\prime \prime}$ S, 47045'27, 1'W, VII/1994, fl. fr., Barreto et al. 2761 (ESA); Itirapina, I/1983, fl. fr., Leitão-Filho et al. s/n (UEC 33144); Jales, I/1950, fl. fr., Hoehne s/n (SPF 12648).

Material adicional examinado: BOLÍVIA. Santa Cruz: Florida, 18¹1'42”'S, 6343'41'W, XII/2002, fl., Mello-Silva et al. 2026 (CTES, LPB, MBM, RB, SPF).

Euploca salicoides apresenta grande variabilidade morfológica, especialmente no hábito, padrão de ramificação e formato da lâmina foliar. Esta gradação provavelmente deve-se a sua ampla distribuição aliada aos ambientes freqüentemente xéricos (caatinga, cerrado e campos rupestres) nos quais se estabelece. As folhas são alternas, espiraladas, ascendentes, pecioladas ou subsésseis. No aspecto geral, apresenta semelhanças com E. fruticosa (L.) J.I.M.Melo \& Semir e E. ternata (Vahl) J.I.M.Melo \& Semir. E. salicoides possui brácteas foliáceas, compartilhadas com E. fruticosa, enquanto que E. ternata apresenta brácteas lineares. Entretanto, E. salicoides diferencia-se de ambas as espécies, especialmente desta última, por apresentar base da lâmina foliar truncada à arredondada, cálice alcançando o comprimento da corola, esta tubular, branca a amarela, com lacínios suborbiculares e pelo fruto estrigoso ou pubérulo. 
Distribui-se na porção oriental da Bolívia, nordeste da Argentina, Paraguai e, no Brasil, nas regiões Nordeste (BA, CE, PE, PI), Centro-Oeste (GO, MT, MS), Sudeste (MG, $\mathrm{SP})$ e Sul (PR, RS). Nos estados do Ceará, Mato Grosso do Sul, Paraná, Pernambuco e no Distrito Federal foi registrada pela primeira vez. É comumente encontrada nos estados da Bahia, Goiás e Minas Gerais, principalmente no bioma Cerrado (cerrado de altitude, campo limpo e campo sujo), formações associadas (campos rupestres, campos de altitude e matas de galeria), em áreas de transição Cerrado-Caatinga (BA), Cerrado-vereda (GO) e Cerrado-mata seca (SP). Na Bahia, também é encontrada em Caatinga, campos gerais e em restinga ao sul do Estado (Caravelas). Está associada a solos arenosos, quartzosos, pedregosos, úmidos e escuros, e em afloramentos rochosos areníticos. Verificou-se, que, nos campos rupestres e de altitude salinos pode ocorrer em elevações de até 1600 metros. Coletada com flores e frutos praticamente todo o ano.

17. Euploca ternata (Vahl) J.I.M.Melo \& Semir, Kew Bull. 64(2): 2009. Heliotropium ternatum Vahl, Symb. Bot. 3: 21. 1794. Tipo: Jamaica, in India occidentali, s.d., s.c. (Holótipo: $\mathrm{GH}$, fotografia!).

Fig. 6: H-N

Subarbusto, $15-30 \mathrm{~cm}$, ereto ou subprostrado, geralmente glauco, ramificado. Ramos cilíndricos, acinzentados ou amarronzados, tomentosos a seríceos, com tricomas esbranquiçados. Folhas alternas, pecioladas ou sésseis; pecíolo 1-2 $\mathrm{mm}$, seríceo, nunca decorrente; lâmina $0,7-3 \times 0,1-0,5 \mathrm{~cm}$, cartácea, estreitamente elíptica, lanceolada a linear, ápice agudo, base aguda, margem levemente a fortemente revoluta, face adaxial esparsa a densamente serícea, face abaxial tomentosa, tricomas longos sobre a nervura principal; venação hifódroma. Inflorescência 1,5-18 cm, terminal e axilar, congesta no ápice, serícea; pedúnculo 1,4-2 cm; brácteas 2,52,7x0,3-0,4 mm, lineares a estreitamente elípticas, margem ciliada, seríceas, inconspícuas. Flores 3-4 mm, subsésseis; cálice profundamente lobado, nunca ultrapassando a porção mediana da corola, lacínios com tamanhos levemente diferentes 2-2,5x0,5-0,7 mm, ovado-elípticos a lanceolados, seríceos em ambas as faces; corola 3-4 mm, tubular, branca, fauce amarela, serícea externamente, tubo 2-2,7 mm, constricção próxima à base e na fauce, lacínios 1,3-2 mm, obovados, estrigosos externamente; estames subsésseis, filetes inseridos na constricção ca. $1 \mathrm{~mm}$ da base do tubo; anteras ca. $1 \mathrm{~mm}$, ovadas, base cordada, ápice longamente-caudado; ovário 0,3-0,4 mm, globoso, glabro; estilete evidente ca. 0,5 $\mathrm{mm}$; estigma $0,6-0,8 \mathrm{~mm}$, estreitamente cônico, 2-fendido no ápice, disco estigmático apresentando diâmetro menor que o do ovário. Esquizocarpo 1,5-1,8 mm diâm., globoso; núculas ca. $1,5 \mathrm{~mm}$ diâm., trígonas, densamente hirsutas, tricomas ferrugíneos. Sementes $1 \mathrm{~mm}$, orbiculares.

Material selecionado examinado: BRASIL. Bahia: Abaíra, X/1999, fl. fr., Miranda \& Silva 289 (HUEFS); Brumado,
II/1990, fl. fr., Miranda et al. 132 (HST); Campo Formoso, IV/1981, fl. fr., Fonseca 382 (HRB); Curaçá, II/1983, fl., Fotius \& Araújo 3348 (IPA); Irecê, V/1984, fl. fr., Fotius 3844 (IPA); Juazeiro, IV/1967, fl., Krapovickas 12889 (CTES); Juçara, IV/1984, fl. fr., Bautista et al. 916 (ALCB, CEPEC, GUA, HRB, HUEFS, MAC, MG, MT); Nova Casa Nova, XII/1987, fl. fr., Moruz 140 (HRB); Sento Sé, I/1990, fl. fr., Miranda \& Esteves 48 (PEUFR). Ceará: Farias Brito, $07^{\circ} 00^{\prime} \mathrm{S}, 39^{\circ} 39^{\prime} \mathrm{W}$, II/1985, fl. fr., Gentry et al. 50200 (EAC, MO); Iguatu, III/1985, fl. fr., Fernandes \& Matos s/n (EAC 13075). Goiás: Posse, II/1990, fl. fr., Arbo et al. 3533 (HRCB); Rodovia Brasília-Fortaleza, I/1965, fl. fr., Belém \& Mendes 106 (CEPEC). Mato Grosso: Corumbá, XII/1976, fl. fr., Krapovickas 29812 (CTES). Minas Gerais: Belo Horizonte, XII/1932, fl. fr., Mello Barreto 2139 (BHCB); Caeté, II/1973, fr., Hatschbach \& Ahumada 31466 (MBM); Diamantina, XI/1937, fl., Mello Barreto 10020 (BHCB); Mocambinho, XII/2004, fl., Hatschbach et al. 78779 (MBM); Pirapora, XII/1937, fl. fr., Burrett et al. 10152 (BHCB, BHMH); Rio Verde, I/1945, fl., Shimoya s/n (VIC 3576); Várzea da Palma, XI/1962, fl. fr., Duarte s/n (CTES 148095, RB 118855). Paraíba: Nazarezinho, IV/1982, fl. fr., Sousa et al. 1174 (JPB); Patos, VI/1935, fr., Pickel 3896 (IPA). Pernambuco: Ibimirim,VI/1995, fl. fr., Ferraz \& Ferreira 04 (IPA); Petrolina, X/1957, fl. fr., Leal Costa s/n (ALCB 3503); Serra Talhada, V/1971, fl. fr., Heringer et al. 635 (PEUFR); Sertânia, VII/2003, fl. fr., Melo 35 (IPA). Piauí: Gilbués, IV/1979, fl., Del'Arco s/n (TEPB 534); São João do Piauí, XII/1978, fl., Freire $s / n$ (TEPB 235); São Raimundo Nonato, $09^{\circ} 00^{\prime}$ S, $42^{\circ} 00^{\prime} \mathrm{W}, \mathrm{I} / 1982$, fl., Lewis \& Pearson 1146 (CEPEC). Rio Grande do Norte: Currais Novos, $06^{\circ} 17^{\prime} \mathrm{S}, 36^{\circ} 32^{\prime} \mathrm{W}$, III/1972, fl. fr., Pickersgill et al. 72-402 (IPA); Mossoró, s/d, fl. fr., Tavares 693 (HST); Serra Negra do Norte, V/2005, fl. fr., Queiroz 285 (PEUFR, UFRN); São Tomé, 0559'30"S, 36¹3'30”W, IV/1980, fl. fr., Oliveira et al. 396 (MOSS). Sergipe: Poço Verde, V/1982, fl. fr., Viana 437 (ASE).

Material adicional examinado: VENEZUELA. Bolivar: Distrito Piar, Paviche, VII/1978, fl. fr., Delascio \& Liesner 7143 (MO, VEN). Mérida: Laderas de San Pablo, IV/1922, fl. fr., Jahn 12520 (VEN).

Euploca ternata exibe expressiva variabilidade morfológica, especialmente com relação ao hábito, ereto ou prostrado, e ao comprimento e formato das folhas, desde estreitamente elípticas, lanceoladas a lineares, com margem levemente a fortemente revoluta. É morfologicamente semelhante a $E$. fruticosa e E. salicoides, especialmente por compartilharem estilete evidente. Distingue-se de ambas as espécies, principalmente desta última, pelas brácteas lineares, inconspícuas, cálice nunca ultrapassando a porção mediana do tubo da corola, esta com lacínios obovados e pelo fruto densamente hirsuto.

Distribui-se desde o México, Antilhas, Guiana Inglesa, Venezuela e, no Brasil, nas regiões Nordeste (BA, CE, PB, PE, PI, RN, SE), Centro-Oeste (GO) e Sudeste (MG). Habita a caatinga hipo-xerofítica e hiper-xerofitica no Nordeste Oriental, em ambientes de transição caatinga-cerrado (BA), cerradão (GO) e 


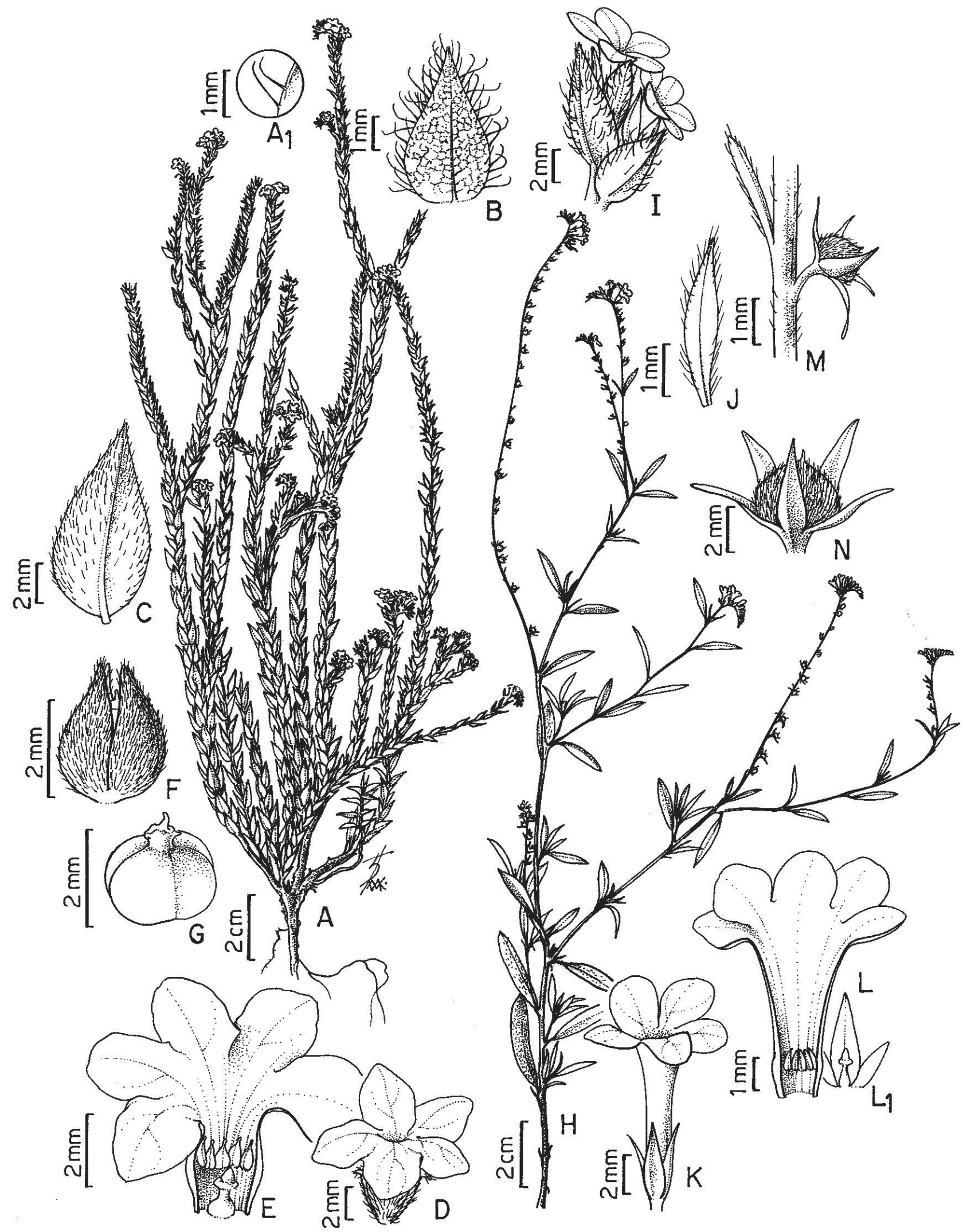

Figura 6. A-N. Euploca salicoides (Cham.) J.I.M.Melo \& Semir (Arbo et al. 3597): A. Ramo reprodutivo, A. Detalhe do indumento. B. Folha. C. Bráctea. D. Flor E. Corola rebatida, evidenciando androceu e gineceu. F. Fruto, evidenciando cálice acrescente. G. Fruto, em vista lateral. E. ternata (Vahl) J.I.M.Melo \& Semir (Miranda et al. 132): H. Ramo reprodutivo. I. Detalhe da inflorescência. J. Bráctea. K. Flor. L. Corola rebatida, evidenciando androceu, L. Gineceu. M. Fruto, evidenciando inserção. N. Fruto, em vista lateral. 
em cerrado de altitude (MG), atingindo o limite meridional de distribuição no norte de Minas Gerais, em vegetação de caatinga. Floresce e frutica entre janeiro e julho e, de outubro a dezembro.

\section{Agradecimentos}

A CAPES (Coordenadoria de Aperfeiçoamento de Pessoal de Nível Superior), pela bolsa de doutoramento concedida a J.I.M. Melo através do PROF/UFRPE. Ao Programa de Pós-Graduação em Botânica/Universidade Federal Rural de Pernambuco (PPGB/UFRPE), pelo apoio durante a execução deste trabalho. Aos curadores dos herbários nacionais e estrangeiros, pelo empréstimo, doação e/ou permissão para consulta das coleções, especialmente aos herbários: Royal Botanic Garden (K), pelo envio de imagens digitalizadas e Gray Herbarium (GH), pela disponibilização on line dos typus através da Dra ${ }^{\mathrm{a}}$. Emily Wood. Ao Dr. Michael Wick Frohlich (Royal Botanic Gardens, Kew) e ao Dr. Harald Förther (Maximilian-Ludwig Universität, Munique, Alemanha), pelo envio de bibliografia, principalmente das descrições originais. Ao Frank Silva, pela confecção das ilustrações.

\section{Referências bibliográficas}

Akhani, H. \& Förther, H. 1994. The genus Heliotropium L. (Boraginaceae) in Flora Iranica. Sendtnera 2: 187-276.

Bentham, G. \& Höoker, J.H. 1873. Boragineae. In: Genera plantarum. V. 2. London, p. 832-865.

Böhle, U.R. \& Hilger, H.H. 1997. Chloroplast DNA systematics of "Boraginaceae" and related families: a goodbye to the old familiar concept of 5 subfamilies. Scripta Botanica Belgica 15: 30 .

Bridson, D. \& Formann, L. 1998. The herbarium handbook. 3.ed. Kew, Royal Botanic Gardens.

Brumitt, R.K. \& Powell, C.E. 1992. Authors of plant names. Kew, Royal Botanic Gardens.

Craven, L.A. 1996. A taxonomic revision of Heliotropium (Boraginaceae) in Australia. Australian Systematics Botany 9: 521-657.

Dalla Torre, C.G. \& Harms, H. 1900. Boraginaceae. Genera siphonogamarum: Systema Englerianum Conscripta. Guilelmi Engelmann, Lipsiae, pp. 424-429.

De Candolle, A.P. 1845. Borragineae. In: Prodromus systematis naturalis regni vegetabilis 9, p. 466-559.

Diane, N.; Förther, H. \& Hilger, H.H. 2002. A systematic analysis of Heliotropium, Tournefortia, and allied taxa of the Heliotropiaceae (Boraginales) based on ITS1 sequences and morphological data. American Journal of Botany 89: 287-295.

Dubs, B. 1998. Boraginaceae. Pp. 40-41. In: B. Dubs (ed.). Prodromus Florae Matogrossensis. The Botany of Mato Grosso, Series B, 3 . Küsnacht, Bertrona-Verlag.

Förther, H. 1998. Die infragenerische Gliederung der Gattung Heliotropium L. und ihre Sterllung innerhalb der sbfam. Heliotropioideae (Schrad.) Arn. (Boraginaceae). Sendtnera 5: 35-241.

Fresenius, G. 1857. Cordiaceae, Heliotropieae, Borragineae. Pp. 1-64. In: C.F.P. Martius, A.G. Eichler \& I. Urban (eds.). Flora brasiliensis. Typographia Regia, Monachii, v. 8, pt. 1.

Frohlich, M.W. 1978. Systematics of Heliotropium sect. Orthostachys in Mexico. PhD. thesis in Biology. Harvard University, Cambridge.

Gangui, N. 1955. Las especies silvestres de Heliotropium de la República Argentina. Revista de la Facultad de Ciencias Exactas, Físicas y Naturales 2: 481-560.

Gottschling, M.; Hilger, H.H.; Wolf, M. \& Diane, N. 2001. Secondary structure of the ITS1 transcription and its application in a reconstruction of the phylogeny of Boraginales. Plant Biology 3: 629-636.

Gray, A. 1874. Contributions to the botany of North America II: notes on Borraginaceae. Proceedings of the American Academy Arts 10: $48-61$.

Guimarães, E.F.; Barroso, G.M.; Ichaso, C.L.F. \& Bastos, A.R. 1971. Flora da Guanabara: Boraginaceae. Rodriguésia 38: 194-220.

Gürke, M. 1893. Borraginaceae. Pp. 49-96. In: A. Engler \& K. Prantl (eds.). Die natürlichen Pflanzenfamilien. Verlag von Wilhelm Engelmann, Leipzig, v. 4, pt. 3 a.
Harris, J.G. \& Harris, M.W. 1994. Plant identification terminology: an illustrated glossary. Utah, Spring Lake Publishing.

Harvey, Y.B. 1995. Boraginaceae. Pp. 155-170. In: B.L. Stannard (ed.). Flora of the Pico das Almas, Chapada Diamantina, Bahia, Brazil. Kew, Royal Botanic Gardens.

Hickey, L.J. 1973. Classification of the architecture of dicotyledonous leaves. American Journal of Botany 60: 17-33.

Hilger, H.H. \& Diane, N. 2003. A systematic analysis of Heliotropiaceae (Boraginales) based on trnL and ITS1 sequence data. Botanische Jahrburcher für Systematik 125: 19-51.

Holmgren, P.K.; Holmgren, N.H. \& Barnett, L.C. 2005. Index herbariorum. Part I. The herbaria of the world. http://sci.web.nybg.org/science2/ IndexHerbariorum.as. Acesso em: 8 fev. 2006.

Johnston, I.M. 1928. The South American species of Heliotropium. Contributions from the Gray Herbarium of Harvard University 81: 3-73.

Johnston, I.M. 1935. Studies in Boraginaceae 10: The Boraginaceae of northeastern South America. Journal of the Arnold Arboretum 16: 1-64.

Johnston, I.M. 1949. Studies in Boraginaceae 18: Boraginaceae of the Southern West Indies. Journal of the Arnold Arboretum 30: 111-138.

Johnston, I.M. 1951. Studies in Boraginaceae 20: Representatives of three subfamilies in eastern Asia. Journal of the Arnold Arboretum 32: 1-26.

Macbride, J.F. 1960. Boraginaceae. In: Flora of Peru. Chicago: Fieldiana, Botany: 539-609.

Melo, E. \& França, F. 2003. Flora de Grão Mogol, Minas Gerais: Boraginaceae. Boletim de Botânica da Universidade de São Paulo 21: $127-129$

Melo, J.I.M. \& Sales, M.F. 2004. Heliotropium L. (Boraginaceae: Heliotropioideae) de Pernambuco, Nordeste do Brasil. Rodriguésia 55: 65-87.

Melo, J.I.M. \& Sales, M.F. 2005. Boraginaceae A. Juss. da região de Xingó: Alagoas e Sergipe. Hoehnea 32: 369-380.

Melo, J.I.M. \& Semir, J. 2006. Euploca rodaliae J.I.M.Melo \& Semir - a new species of Euploca (Heliotropiaceae) from Brazil. Candollea 61: 453-456.

Melo, J.I.M. 2006. Boraginaceae. P. 49. In: M.R.V. Barbosa; C. Sothers; S. Mayo; C.F.L. Gamarra-Rojas \& A.C. Mesquita (eds.). Checklist das plantas do Nordeste brasileiro: Angiospermas e Gymnospermas. Brasília, Ministério da Ciência e Tecnologia.

Melo, J.I.M. \& Andrade, W.M. 2007. Boraginaceae s.l. A. Juss. em uma área de Caatinga da ESEC Raso da Catarina, BA, Brasil. Acta Botanica Brasilica 21: 369-378.

Mendonça, R.C.; Felfili, J.M.; Fagg, C.W.; Silva, M.A.; Filgueiras, T.S. \& Walter, B.M.T. 2000. Florística da região do Espigão Mestre do São Francisco, Bahia e Minas Gerais. Boletim do Herbário Ezechias Paulo Heringer 6: 38-94.

Munhoz, C.B.R. \& Proença, C.E.B. 1998. Composição florística do município de Alto Paraíso de Goiás na Chapada dos Veadeiros. Boletim do Herbário Ezechias Paulo Heringer 3: 102-150.

Nagatani, Y. \& Rossi, L. 2000. Flora fanerogâmica da Reserva do Parque Estadual das Fontes do Ipiranga-São Paulo, Brasil: 141-Boraginaceae. Hoehnea 27: 95-98.

Nuttall, T. 1837. Collections towards a flora of the territory of Arkansas. Transactions of the American Philosophical Society 5: $137-203$

Payne, W.W. 1978. A glossary of plant hair terminology. Brittonia 30: 239-255.

Radford, A.E.; Dickison, W.C.; Massey, J.R. \& Bell, C.R. 1974. Vascular plant systematics. Harper \& Row Publishers, New York.

Riedl, H. 1966. Die gattung Heliotropium in Europa. Annalen des Naturhistorischen Museums in Wien 69: 81-32.

Rizzini, C.T. 1977. Sistematização terminológica da folha. Rodriguésia 29: $103-125$.

Rodríguez, G. 1993. El género Heliotropium L. (Boraginaceae) en Venezuela. Sinopsis. Acta Botánica Venezoélica 16: 83-91.

Rua, G.H. 1999. Inflorescencias: bases teóricas para su análisis. Buenos Aires, Sociedad Argentina de Botânica.

Sano, S.M. \& Almeida, S.M.P. (eds.). 1998. Cerrado: ambiente e flora. Empresa Brasileira de Pesquisa Agropecuária, Centro de Pesquisa Agropecuária do Cerrado, Planaltina.

Smith, L.B. 1970. Boragináceas. In: R. Reitz (ed.). Pp. 3-85. Flora ilustrada catarinense. Itajaí, Herbário Barbosa Rodrigues. 
Strasburger, E.A.; Noll, F. \& Rudolf, J.H. 1974. Tratado de botánica. Barcelona, Editorial Marin.

Webberling, F. 1995. Morphology of flowers and inflorescences. Cambridge, Cambridge University Press.
Zappi, D.C.; Lucas, E.; Stannard, B.L.; Lughada, E.N.; Pirani, J.R.; Queiroz, L.P.; Atkins, S.; Hind, D.J.N.; Giulietti, A.M.; Harley, R.M. \& Carvalho, A.M. 2003. Lista das plantas vasculares de Catolés, Chapada Diamantina, Bahia, Brasil. Boletim de Botânica Universidade de São Paulo 21: 345-398. 